\title{
NanoBRET in C. elegans illuminates functional receptor interactions in real time
}

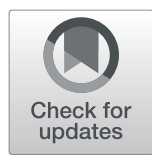

\author{
Victoria Elisabeth Groß ${ }^{1,2}$, Miron Mikhailowitsch Gershkovich³ ${ }^{3}$ Torsten Schöneberg ${ }^{1}$, Anette Kaiser ${ }^{3^{*}}$ and \\ Simone Prömel ${ }^{1,2^{*}}$ (D)
}

\begin{abstract}
Background: Protein-protein interactions form the basis of every organism and thus, investigating their dynamics, intracellular protein localization, trafficking and interactions of distinct proteins such as receptors and their ligandbinding are of general interest. Bioluminescence resonance energy transfer (BRET) is a powerful tool to investigate these aspects in vitro. Since in vitro approaches mostly neglect the more complex in vivo situation, we established BRET as an in vivo tool for studying protein interactions in the nematode C. elegans.

Results: We generated worms expressing NanoBRET sensors and elucidated the interaction of two ligand-G protein-coupled receptor (GPCR) pairs, the neuropeptide receptor NPR-11 and the Adhesion GPCR LAT-1. Furthermore, we adapted the enhanced bystander BRET technology to measure subcellular protein localization. Using this approach, we traced ligand-induced internalization of NPR-11 in vivo.

Conclusions: Our results indicate that in vivo NanoBRET is a tool to investigate specific protein interactions and localization in a physiological setting in real time in the living organism C. elegans.
\end{abstract}

Keywords: NanoBRET, C. elegans, Receptor-ligand interaction, Enhanced bystander BRET

\section{Background}

The investigation of protein-protein interactions is of great interest to scientists of many fields since they are crucial for most physiological processes and thus, also represent a focus in drug discovery. Monitoring interactions, protein localization and intracellular trafficking has become increasingly feasible in the past years with the development of several tools, among others bioluminescence resonance energy transfer (BRET) (summarized in $[1,2])$. BRET relies on a donor emitting bioluminescence and a fluorescent acceptor. The donor is usually an enzyme catalyzing the reaction of a luminogenic substrate. In this reaction, light is emitted and the energy is

\footnotetext{
* Correspondence: anette.kaiser@uni-leipzig.de; proemel@uni-duesseldorf.de ${ }^{3}$ Institute of Biochemistry, Faculty of Life Sciences, Leipzig University, 04103 Leipzig, Germany

${ }^{1}$ Rudolf Schönheimer Institute of Biochemistry, Medical Faculty, Leipzig University, 04103 Leipzig, Germany

Full list of author information is available at the end of the article
}

transferred to a suitable acceptor in close proximity $(<10$ $\mathrm{nm}$ ), which emits fluorescence upon excitation. These "tags" are used to study the interaction of proteins when they are fused to them. Common BRET pairs are luciferases and fluorescent proteins such as the green fluorescent protein (GFP) [3, 4]. The extensive use of BRET led to a continuous optimization of the system. The newest achievement is the small engineered Nanoluciferase (Nluc), which is much smaller (19 kD) than the widely used Rluc from Renilla reniformis (36 kD) or the firefly Fluc (61 kD), making it ideal for fusions with other proteins. Further, it provides a 150-fold higher/more intense luminescence than other luciferases [5]. The resulting BRET is referred to as NanoBRET [6] and is more sensitive and versatile than BRET approaches using Rluc or Fluc.

BRET has been very successfully employed to investigate general protein-protein interactions in living cells (reviewed in [6]), intracellular trafficking $[7,8]$, conformational 
changes [9] and dimerization $[10,11]$ of proteins. One main area of BRET applications is the investigation of ligandreceptor binding (reviewed in $[2,12])$. To date, BRET studies are mainly restricted to cell culture. The use of this method in animal models is rare for several reasons such as poor tissue accessibility or signal intensity and duration and more laborious manageability (summarized in [13]). However, application of the BRET technology in vivo offers the opportunity to study protein interactions or ligand-receptor binding in a more complex cellular environment. This is especially of advantage when co-factors or other, unidentified molecules are required to e.g. stabilize ligand-binding. These might not be present in a cell-based environment, but are naturally present in the endogenous setting of the proteins to be studied. Thus, special BRET approaches closer to in vivo settings have been used to monitor for instance tumor growth in mice, where luciferase-expressing cells were injected into the animals [14-17]. Furthermore, BRET is traceable also in vivo by co-injecting fluorescent ligands or fusion proteins $[18,19]$. Nevertheless, in vivo BRET studies in animals directly expressing a luciferase as a BRET donor do not exist to our knowledge, including common model organisms such as fish $(D$. rerio), fly ( $D$. melanogaster) or worm (C. elegans). However, these animals are not only suitable models for many physiological processes, but also bear many advantages such as being small and easily cultivated. Thus, BRET studies would be highly beneficial to address questions on protein-protein interactions, protein trafficking, subcellular localization, and ligand-binding of receptors in a broader cellular and organismal context.

Among these model organisms, the nematode C. elegans stands out as most suitable to implement the BRET method in vivo since it is completely translucent and easy to genetically manipulate. Measuring bioluminescence as a marker, for example for ATP concentrations [20] or gene expression [21], is already a common tool and the use of fluorescent markers is also well established in C. elegans [22].

Therefore, our aim was to establish specific NanoBRET sensors in C. elegans for the investigation of protein-protein interactions as well as protein localization in vivo. As receptor-ligand binding studies are to date the most common fields of application for BRET, we chose two very different $G$ protein-coupled receptors (GPCR) and their ligands: the neuropeptide receptor NPR-11 with its ligand FLP-34-1 and the Adhesion GPCR LAT-1 with a synthetic peptide derived from a tethered agonistic sequence buried within the receptor. NPR-11 possesses the closest sequence and pharmacological similarities to the well-characterized human neuropeptide Y (NPY)/neuropeptide F (NPF) system [23], which is conserved in almost all bilaterians and has essential physiological functions in regulating food uptake and learning (reviewed in [24-27]). NPR-11 is activated by several neuropeptides, among others by FLP34-1, which has conserved structural motifs similar to NPY [23, 28].

The second GPCR, the Adhesion GPCR LAT-1 is one worm homolog of Latrophilins and has neuronal (summarized in [29]) and developmental [30, 31] functions. The receptor is activated by a tethered agonist sequence (termed Stachel), which is located within the $\mathrm{N}$ terminus of the receptor [32]. Peptides derived from this sequence are also able to activate LAT-1 [31].

To enable BRET-based ligand binding assays, both receptors were fused to a Nanoluciferase (Nluc) [5] at their $\mathrm{N}$ terminus serving as energy donor. Their corresponding ligands were tagged with the fluorescent 5(6)-carboxytetramethylrhodamine (TAM) as energy acceptor. Using this assay, we show interaction for both ligand-receptor pairs, but highlight that low-affinity binding is difficult to determine in this in vivo system.

Additionally, we have adapted and tested an enhanced bystander NanoBRET assay [8] to elucidate subcellular localization and recycling of NPR-11, which relies on spatial proximity between a plasma membrane marker based on an mNeonGreen (mNG) fluorophore fused to the CAAX-targeting sequence (polybasic sequence containing a prenylation sequence), and NPR-11 fused C-terminally to the Nluc. This revealed a temporal reduction of NPR-11 in the plasma membrane after stimulation with its ligand FLP-34-1, suggesting receptor internalization.

\section{Results}

Luminescence of a BRET donor-fusion protein depends on the protein of interest and nematode condition

One essential pre-requisite for a stable BRET signal is a bright and constant luminescence signal of the donor. In order to establish BRET analyses in C. elegans, we first sought to optimize the luminescence signal intensity emitted from the donor, which is highly dependent on the accessibility of the donor itself and the availability of the substrate converted by the donor. To ensure these aspects, we generated nematodes stably expressing a Nanoluciferase (Nluc) [5] as donor fused to the extracellular $\mathrm{N}$ terminus of NPR-11 (Nluc::NPR-11, the strain is referred to as Nluc::npr-11 as well as the transcript) and LAT-1 (Nluc::LAT-1, the strain is termed Nluc::lat-1 as well as the transcript), respectively (Fig. 1A). A SGGGGS linker provided some conformational flexibility of the Nluc. Expression of these constructs was confirmed by fluorescence confocal microscopy. It has to be noted that expression pattern of $n p r-11$ is not as complete as described by others [28]. This is most likely because the construct used in our study contains a $3 \mathrm{~kb}$ promoter. A longer sequence could yield a broader expression pattern. 


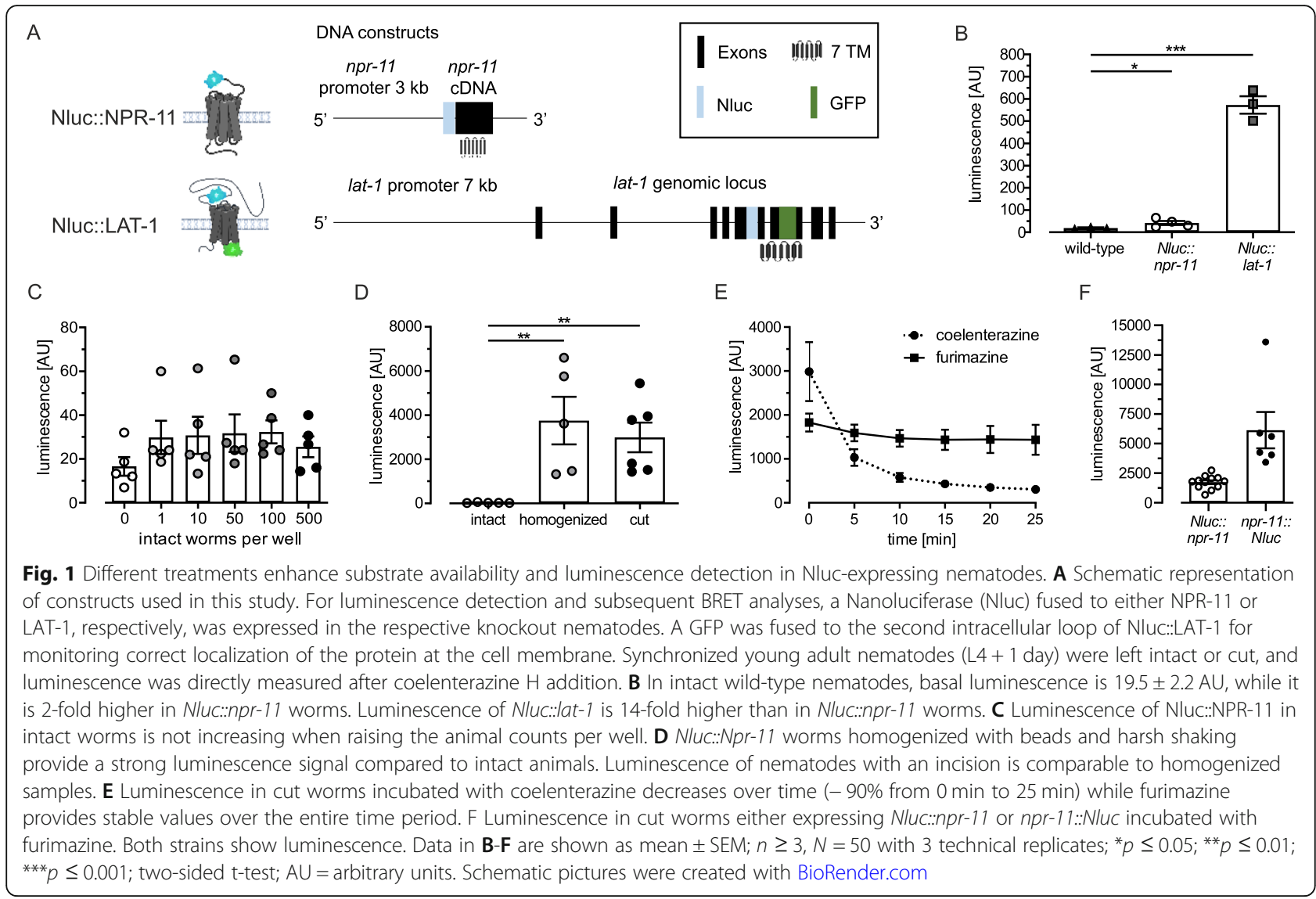

While the fluorescence of Nluc::NPR-11::GFP was limited to two cells (presumably neurons) within the nematode tail (Fig. S1A), Nluc::lat-1::GFP expression was detected around the membrane of pharyngeal muscles (Fig. S1B).

Different set-ups were assessed to determine the one providing the most intensive and stable luminescence signal while at the same time keeping the nematodes as intact as possible and the number of animals to a minimum. To enable a reliable quantification, these analyses were conducted using a plate reader. First, we studied the luminescence intensity of 50 synchronized intact, viable animals ( $L 4+1$ day). A signal was detected in both strains, Nluc::npr-11 and Nluc::lat-1, which was significantly increased compared to the one of the wild-type after incubation with the substrate coelenterazine $\mathrm{H}$ (Fig. 1B). The luminescence of Nluc::LAT-1 was 14-fold higher than the signal of Nluc::NPR-11, probably due to the difference in expression levels and patterns of both receptors. The signal of the Nluc::npr-11-expressing nematodes was only slightly above background (Fig. 1B), yielding suboptimal conditions for further analyses. Thus, we sought to optimize the luminescence signal of this strain to make the technique amenable also for lowly expressed genes. Firstly, we altered the number of animals per well to check whether this correlates with luminescence intensity (Fig. 1C). However, increasing amounts of worms did not render a higher luminescence signal. The reason for this might be that blue-shifted light is scattered by tissue [33], thus perturbing any increase in signal, or limited diffusion of the substrate across the cuticle.

Secondly, we aimed at elevating substrate availability within a sample. Sfarcic et al. have previously reported that detection of luminescence is greatly increased in lysed worms [21]. Thus, we ruptured the nematodes to facilitate substrate distribution. As we aimed at keeping the cells as intact and viable as possible, we compared two different approaches: homogenization, and making an incision with a scalpel (Fig. 1D). Both techniques significantly increased the luminescence up to 3000-4000 AU (Fig. 1D). As cutting an incision kept the worms mostly intact and proved to provide sufficient luminescence signal, all following analyses in this study were conducted using the incision method to prepare worms.

Finally, we evaluated whether the luminescence signal can be improved by using a different substrate. Coelenterazine $\mathrm{H}$ lost its activity over time when used on worms, reaching $10 \%$ of the initial value after $25 \mathrm{~min}$ (Fig. 1E). Therefore, an alternative substrate optimized 
for brightest luminescence with the nanoluciferase, furimazine [5], was tested, resulting in a lower but more stable luminescence signal (Fig. 1E). Thus, for subsequent studies, assays were performed with furimazine. Further, we verified that furimazine enters the cells in the worm by assaying a strain expressing npr-11::Nluc and found that the luminescence signal is not weaker than in the strain Nluc::npr-11 carrying the Nluc at the extracellular $\mathrm{N}$ terminus of NPR-11 (Fig. 1F).

Taken together, our analyses showed that bioluminescence can be reliably measured in small quantities of nematodes expressing Nluc fused to proteins. Signals from proteins with lower expression levels can be analyzed when using the incision method to prepare the worms and furimazine as substrate. These data formed to basis for subsequent BRET analyses.

\section{Tetramethylrhodamine-labeled peptides as BRET acceptors}

Besides the energy donor, an acceptor is required in order to enable BRET analyses. Peptide-activated GPCR are highly suitable for BRET studies because both receptors and ligands can be easily labeled. Furthermore, receptors are well-accessible at the cell surface and peptides can be applied in a relatively simple manner compared to other ligands.
We labeled the peptide ligands of NPR-11 and LAT-1 (FLP-34-1 for NPR-11 and pLAT-1 for LAT-1) with the fluorescent tetramethylrhodamine (TAM), which served as energy acceptor and fluorescent tracer. To check that these TAM-labeled peptides penetrate the tissue and distribute equally, the fluorescence signal in pre-treated intact worms and in nematodes with an incision was determined (Fig. 2, Fig. S2). For that purpose, the TAM label was directly excited and fluorescence detected in the heads of animals treated with either TAM-FLP-34-1 or a scrambled control version (TAM-scrFLP-34-1, random composition of the same amino acids resulting in comparable chemical properties). While in intact worms, fluorescence was only detectable within the lumen of the pharynx up to the terminal bulb for both peptides (Fig. $2 \mathrm{~A}, \mathrm{~B}$ ), it was spread in the entire pseudocoelom and even accumulated on some structures in worms with incisions incubated with TAM-FLP-34-1 (Fig. 2C, white arrows). These patterns did not appear during the incubation with TAM-scrFLP-34-1 (Fig. 2D), indicating a specific distribution of TAM-FLP-34-1. TAM-pLAT-1 showed a similar pattern (Fig. S2A, C), however, no difference to TAM-scrpLAT-1 was detected (Fig. S2B, D). These results indicate that TAM-labeled peptides do not enter the nematodes properly when simply fed, but penetrate worms with incisions.

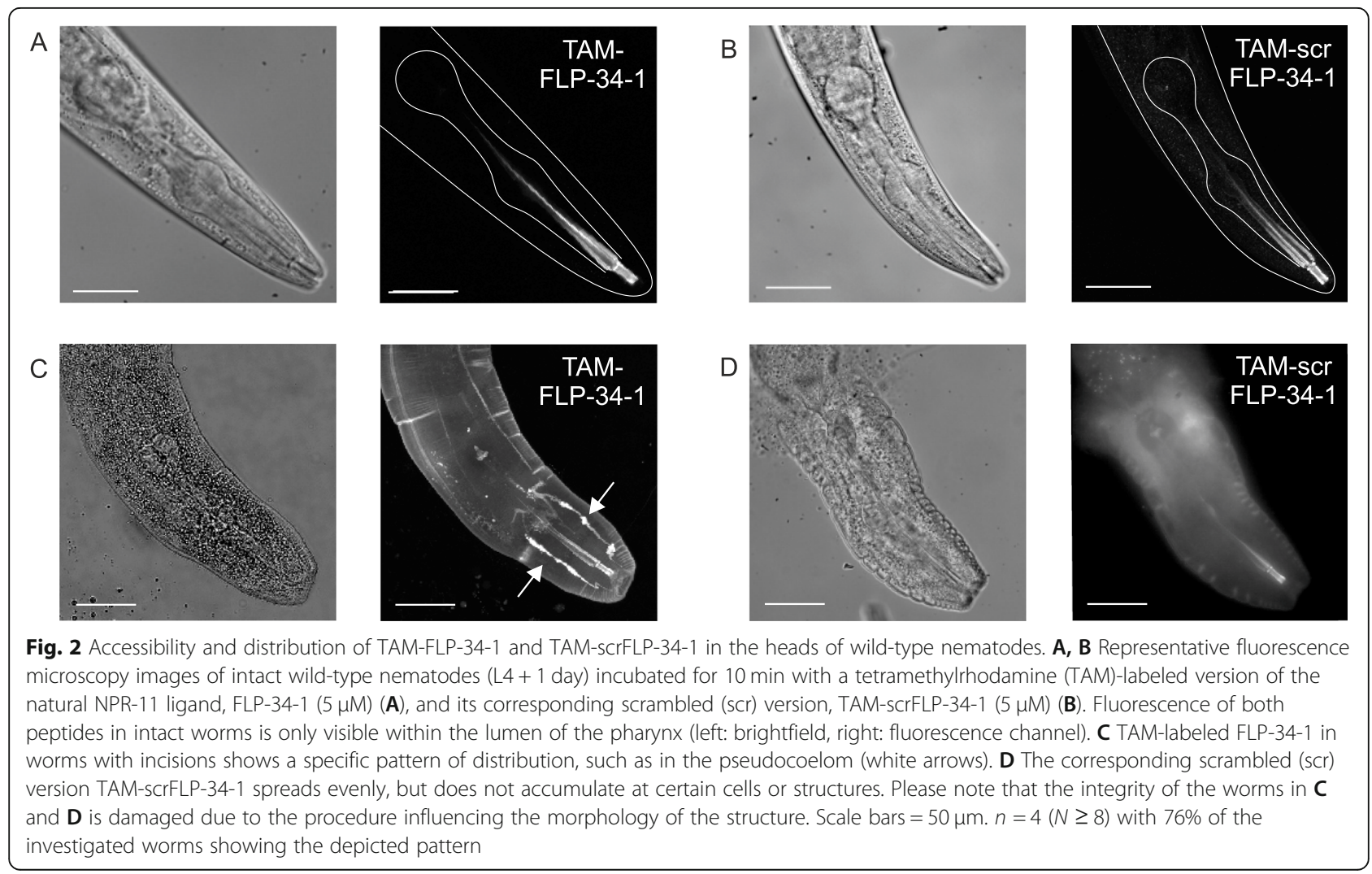


Next, we verified that the TAM label does not disturb binding of the peptides and their capability to activate NPR-11. As the conserved bioactive part of FLP neuropeptides resides in their $\mathrm{C}$ terminus [23, 34], any modifications to the free $\mathrm{N}$ terminus of FLP-34-1 were expected to be tolerated. This proved to be the case when we elucidated the activity in cell culture using a NanoBRET assay for elucidating binding properties and a cAMP reporter gene assay for analyzing activation (Fig. S3). It was previously shown that FLP-34-1 is a potent endogenous ligand of NPR-11 [23, 28]. In our NanoBRET assay set-up, adding TAM-FLP-34-1 in increasing concentrations to Nluc::NPR-11 led to the formation of a specific BRET window of $0.29 \pm 0.01$ (difference between donor-only and donor/acceptor values, i.e. unstimulated/stimulated samples) with a $K_{d}$ value of $388 \mathrm{nM}$. TAM-scrFLP-34-1 yielded no signal above baseline levels up to concentrations of $3 \mu \mathrm{M}$ (Fig. S3A). These data are consistent with previously performed competition-binding assays using TAM-FLP-34-1 as fluorescent tracer, in which unmodified FLP-34-1 displays an inhibition binding constant $\mathrm{K}_{\mathrm{i}}$ of $107 \mathrm{nM}$ [35]. This is comparable to the $K_{d}$ value of the fluorescently labeled peptide, and thus, corroborates the wild type-like properties of TAM-FLP-34-1.

To evaluate the ability of the TAM-labeled peptides to activate NPR-11, a cAMP reporter gene assay was performed. Activity of GPCR is detectable through their binding to $G$ proteins and the subsequent change in second messenger concentrations. Since NPR-11 couples to $G_{i}$ proteins, pre-stimulation with forskolin (an activator of the cAMP-producing adenylyl cyclase) was necessary to increase intracellular cAMP levels and measure the ability of NPR-11 to inhibit this process. Changes in intracellular cAMP levels can be determined by a reporter gene assay. In this assay, TAMFLP-34-1 showed the capability to activate NPR-11 $\left(\mathrm{EC}_{50}=0.5 \mathrm{nM}\right)$ similar to the one of the unmodified peptide $\left(\mathrm{EC}_{50}=2.3 \mathrm{nM}\right)$, while the scrambled peptide (TAM-scrFLP-34-1) did not activate NPR-11 (Fig. S3B) and served as negative control.

To activate LAT-1, we used a synthetic peptide derived from the tethered agonist sequence [31]. To generate a fluorescently-labeled version (TAM-pLAT-1), the TAM fluorophore was attached in the C-terminal part of the peptide to minimize functional interferences as it has been shown that the free $\mathrm{N}$-terminal threonine is important for the agonistic properties of the peptide [36]. A cAMP accumulation assay revealed that TAMpLAT-1 harbored the same activity as unlabeled pLAT-1 (cAMP accumulation 1.5-fold over control at a concentration of $100 \mu \mathrm{M}$, Fig. S3C). The respective scrambled peptide TAM-scrpLAT-1 did not lead to a cAMP accumulation at the same concentration (Fig. S3C).
These data clearly indicate that TAM labeling did not alter binding or activity of the peptides they are conjugated with and thus, they can be employed for in vivo BRET analyses.

\section{The interaction between TAM-labeled peptides and Nluc- fused receptors can be monitored by BRET}

Based on the findings, settings and approaches described above, an experimental set-up was established to measure BRET in vivo in C. elegans. BRET pairs were generated between the Nluc-fused receptors (Nluc::NPR11; Nluc::LAT-1) and their ligands (FLP-34-1; pLAT-1) or scrambled versions (scrFLP-34-1; scrpLAT-1) conjugated with TAM (Fig. 3A). In these experiments, the number of animals per well was reduced to 30 as the luminescence intensity was still sufficient $(>500 \mathrm{AU})$ to achieve a measurable BRET window (Table S1).

Synchronized nematodes (L $4+1$ day) with an incision expressing Nluc::npr-11 were treated with TAM-FLP-341 and a robust BRET signal was observed. We also detected a BRET signal when using the scrambled control peptide TAM-scrFLP-34-1 (Fig. 3B). However, the increase in the BRET ratio by TAM-FLP-34-1 was higher than by TAM-scrFLP-34-1 (TAM-FLP-34-1 = $0.08 \pm 0.012$; TAM-scrFLP-34- $1=0.07 \pm 0.003$; at $10 \mu \mathrm{M}$ ) (Fig. 3B, left panel). To calculate the specific binding of TAM-FLP-34-1 to Nluc::NPR-11, we treated the BRET signals of the scrambled peptide control as nonspecific binding (cf. Fig. S3, which shows that the scrambled version of FLP-34-1 has no measurable affinity and activity to NPR-11 in vitro), and calculated the netBRET by subtracting the TAM-scrFLP-34-1 BRET ratio from the respective TAM-FLP-34-1 BRET ratio. This showed that a specific BRET window opens starting from around $1 \mu \mathrm{M}$ peptide concentration, which was saturable with increasing concentrations (Fig. 3B, right panel). Accordingly, the $K_{d}$ value of TAM-FLP-34-1 in vivo was calculated to be $1.4 \mu \mathrm{M}$, which was 4 -fold higher, but still in reasonable agreement with the $K_{d}$ value determined in vitro (in vitro: $388 \mathrm{nM}$ ). We assume that the BRET effect of the scrambled control peptide is a result of the more complex in vivo situation, in which this peptide variant might bind to other protein targets in the vicinity of NPR-11, thus causing BRET without directly interacting with NPR-11.

To substantiate that binding of TAM-FLP-34-1 to Nluc:: NPR-11 is specific, a displacement binding study was conducted, in which the amount of unlabeled FLP-34-1 was increased while the concentration of TAM-FLP-34-1 remained constant. FLP-34-1 displaced TAM-FLP-34-1 with a $K_{i}$ value of $1.1 \mu \mathrm{M}$ indicating a specific binding of the peptides (Fig. 3C). Taken together, stable NanoBRET is generated while endogenously expressing the Nluc-fused $n p r-11$ and administering TAM peptides. 


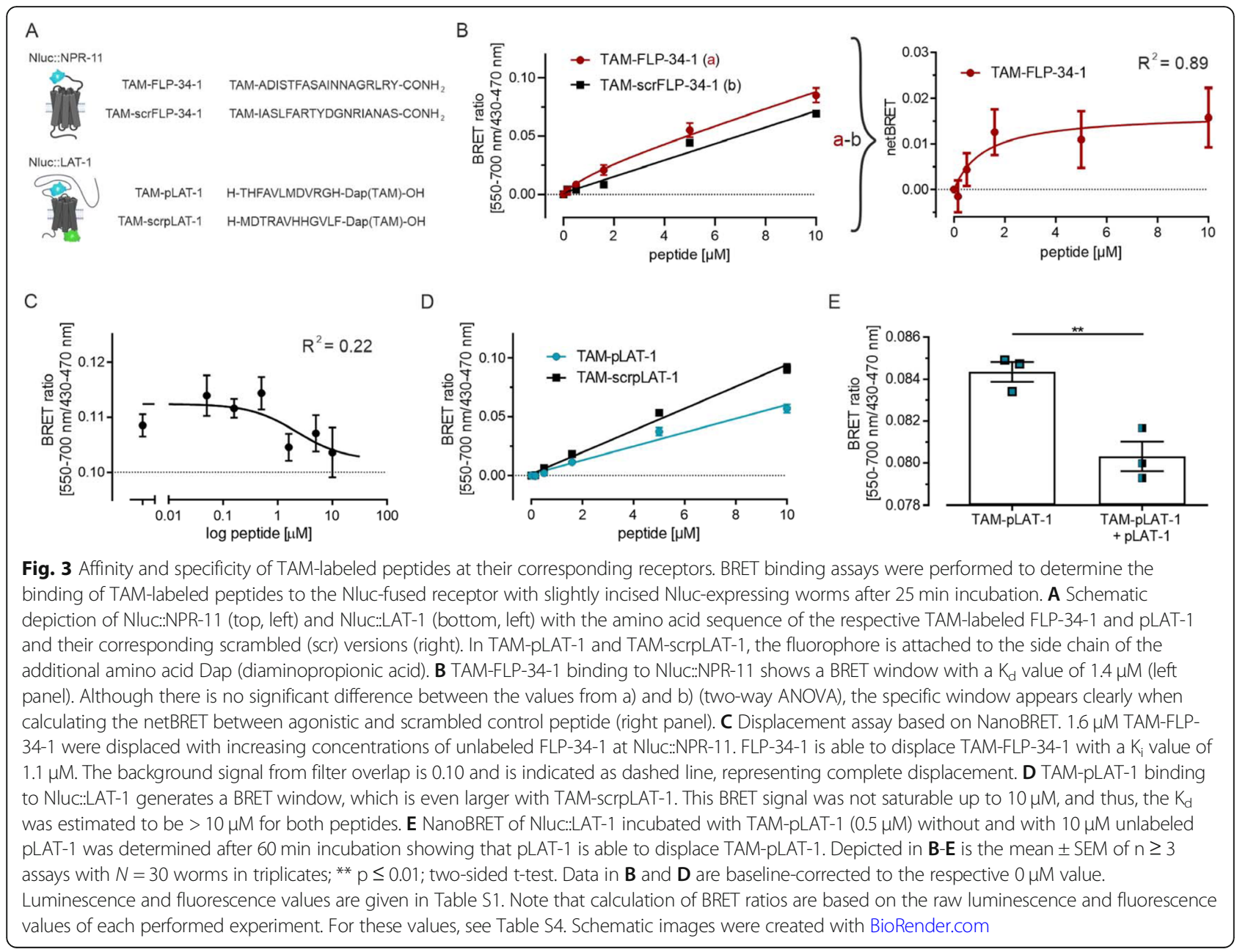

To further investigate the potential of NanoBRET in $C$. elegans, we assessed the second receptor-peptide pair, Nluc::LAT-1 and pLAT-1, which has a reportedly lower potency and typically requires approximately $1 \mathrm{mM}$ peptide to activate the receptor [31]. Incubation of Nluc::lat1-expressing worms with TAM-pLAT-1 generated robust BRET windows that increased with rising peptide concentrations (Fig. 3D). Surprisingly, the scrambled control TAM-scrpLAT-1, which proved inactive in in vitro signaling assays (Fig. S3C), provided an even stronger increase in BRET signal with a one-third higher BRET ratio at $10 \mu \mathrm{M}$ than TAM-pLAT-1. In both cases, the BRET signal was not saturable up to $10 \mu \mathrm{M}$, and thus, the $\mathrm{K}_{\mathrm{d}}$ value was estimated to be $>10 \mu \mathrm{M}$ (Fig. 3D). Similar to the situation with the scrambled version of FLP-34-1 described above, we assumed that the BRET signal of the scrambled pLAT- 1 originated from binding to proteins in the vicinity of LAT-1, or attaching to other sites in LAT-1. The presumably low binding affinity of pLAT-1 prevented the calculation of specific binding by subtracting the signal of the scrambled peptide in this case. However, the different BRET windows for TAM-pLAT-1 versus TAM-scrpLAT-
1 suggest that the peptides occupy different sites, and TAM-pLAT-1 might be enriched at a site with less efficient BRET compared to random orientations in unspecific binding of TAM-scrpLAT-1.

To gain further information on the specificity of TAMpLAT-1, the ability of unlabeled pLAT-1 to displace TAM-pLAT-1 was monitored (Fig. 3E). After $60 \mathrm{~min}$ of incubation, we found a partial reduction of the BRET signal in the presence of excess unlabeled pLAT-1. These data suggest that partial displacement is occurring.

To conclude, these data show that NanoBRET measurements are feasible to estimate binding affinities in vivo within the nematode, and work particularly well for high-affinity interactions with $K_{d}$ values up to the low micromolar range.

\section{Enhanced bystander BRET in vivo reveals potential internalization of NPR-11}

Besides direct interactions, the subcellular localization of proteins as well as the proximity to other proteins are of great interest. In vitro studies do not completely reflect the situation in vivo, since the proteins are not in their 
natural environment. Therefore, we adapted the enhanced bystander BRET methodology in vivo to examine subcellular localization of proteins. Here, NPR$11 \mathrm{C}$-terminally fused to the Nluc was chosen as energy donor while the green fluorescent protein mNeonGreen (mNG) fused to the CAAX motif from let-60 served as energy acceptor (Fig. 4A). let-60 encodes for a human KRas homolog (GTPase) present at the plasma membrane. The CAAX motif serves as a plasma targeting sequence and prenylation signal, ensuring correct localization of a protein at the plasma membrane (summarized in [37]). We generated a worm strain stably expressing mNeonGreen at the plasma membrane of all cells (expression driven by the strong ribosomal promoter $r p l-28 p$ ) (schematic representation in Fig. 4A, expression in Fig. S4). Enhanced bystander BRET was detected by comparing the donor-only-expressing strain with worms harboring both, donor and acceptor. The donor-only strain provided a stable 'BRET' baseline around $0.28 \pm 0.01$, which was the experimental background due to filter overlap and potential induction of background fluorescence in the cellular background. In the presence of donor and acceptor, the BRET signal was elevated to $0.32 \pm 0.01$ (Fig. 4B), demonstrating that a productive BRET is occurring due to the proximity of the receptor and plasma membrane marker, yielding a net measurement window of approximately 0.04 BRET units.

Interestingly, when treated with (unlabeled) FLP-34-1, worms carrying donor and acceptor showed a decrease of BRET signal compared to untreated controls over time (Fig. 4C). Luminescence and fluorescence were monitored over $80 \mathrm{~min}$ and a significant BRET window between FLP-34-1-treated and -untreated worms appeared between 50 and $70 \mathrm{~min}$. This lower BRET signal in animals incubated with FLP-34-1 suggests a distancing from donor and acceptor. Since CAAX::mNG is permanently localized to the plasma membrane (Fig. S4) [8], the reduced BRET signal is likely caused by the dynamic removal of NPR-11::Nluc from the membrane upon activation. This effect reflected ligand-induced internalization followed by either receptor recycling or de novo synthesis of receptors to re-establish NPR-11 pools in the plasma membrane and was consistent with the subcellular trafficking of NPR-11 observed in vitro. To verify this observation, NPR-11 fused to an enhanced cyan fluorescent protein (eCFP) and the CAAX::mNG membrane marker were co-expressed in HEK293 cells, stimulated with its peptide ligand and receptor and marker localization were monitored by fluorescence microscopy (Fig. 5A). Before stimulation, NPR-11::CFP was present almost exclusively at the plasma membrane. 30 min after TAM-FLP-34-1 application, receptor clusters appeared in vesicular structures such as endosomes and co-localized with TAM fluorescence. Those clusters became even more pronounced after $60 \mathrm{~min}$ (Fig. 5A), suggesting ligand-induced internalization of NPR-11. Consistent with this observation, quantification of membrane fluorescence of NPR-11::eCFP and CAAX::mNG in the same cells confirmed receptor internalization (Fig. $5 B)$, while CAAX::mNG remained at the plasma membrane as expected. After agonist wash-out, the receptor fluorescence slightly increased again, which might be due to receptor recycling or biosynthesis. To further investigate this effect, co-localization of NPR-11::eYFP with different cell compartments was determined. Colocalization with lysosomes was partially visible for the
A

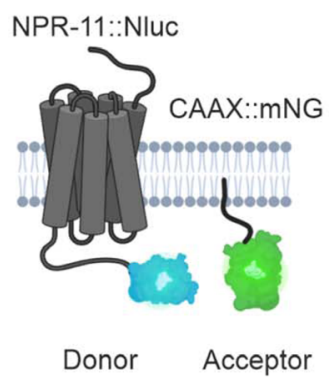

B

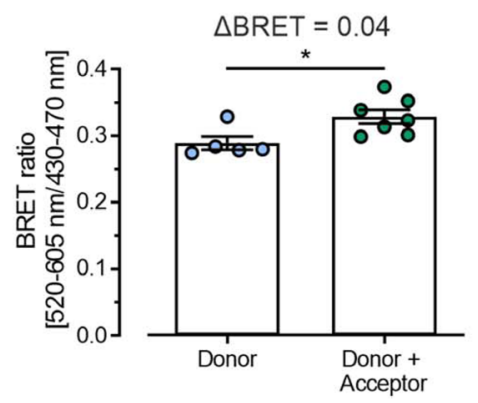

C

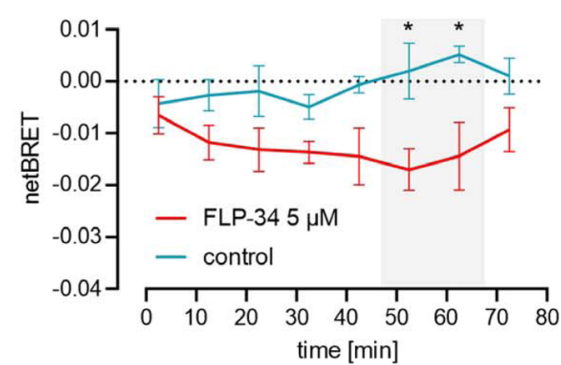

Fig. 4 Enhanced bystander BRET reveals information on receptor trafficking and internalization of NPR-11 in vivo. A Bystander BRET was determined between Nluc fused to the C terminus of NPR-11 (NPR-11:NNluc, donor) and an mNeonGreen fused to the C-terminal part of let-60 (CAAX::mNG, acceptor) expressed in the same individual. B Donor and acceptor are generating a bystander BRET signal that is significantly higher than the donor-only (baseline) BRET ratio. Experiments were set-up as in Fig. 3. Luminescence and fluorescence values are given in Table S1. Shown is the mean \pm SEM in $n \geq 5$ assays with 30 worms per well as triplicates; ${ }^{*} p \leq 0.05$ two-sided t-test. C Enhanced bystander BRET (measured over time) of worms treated either with BSA or $5 \mu \mathrm{M}$ FLP-34-1, baseline-corrected (value - baseline) for every single time point and pruned rows (mean of every $10 \mathrm{~min}$ value with the following value starting with $t=2.5 \mathrm{~min}$ ). While the control stays stable around the baseline, the netBRET of FLP-34-1 drops after $42.5 \mathrm{~min}$, opening a significant window till $62.5 \mathrm{~min}$ (grey area), suggesting a separation of donor and acceptor. Shown is the mean \pm SEM in $n=3$ assays with 30 worms per well as triplicates; ${ }^{*} p \leq 0.05$ two-way ANOVA, Bonferroni's posthoc test. Schematic images were created with BioRender.com 


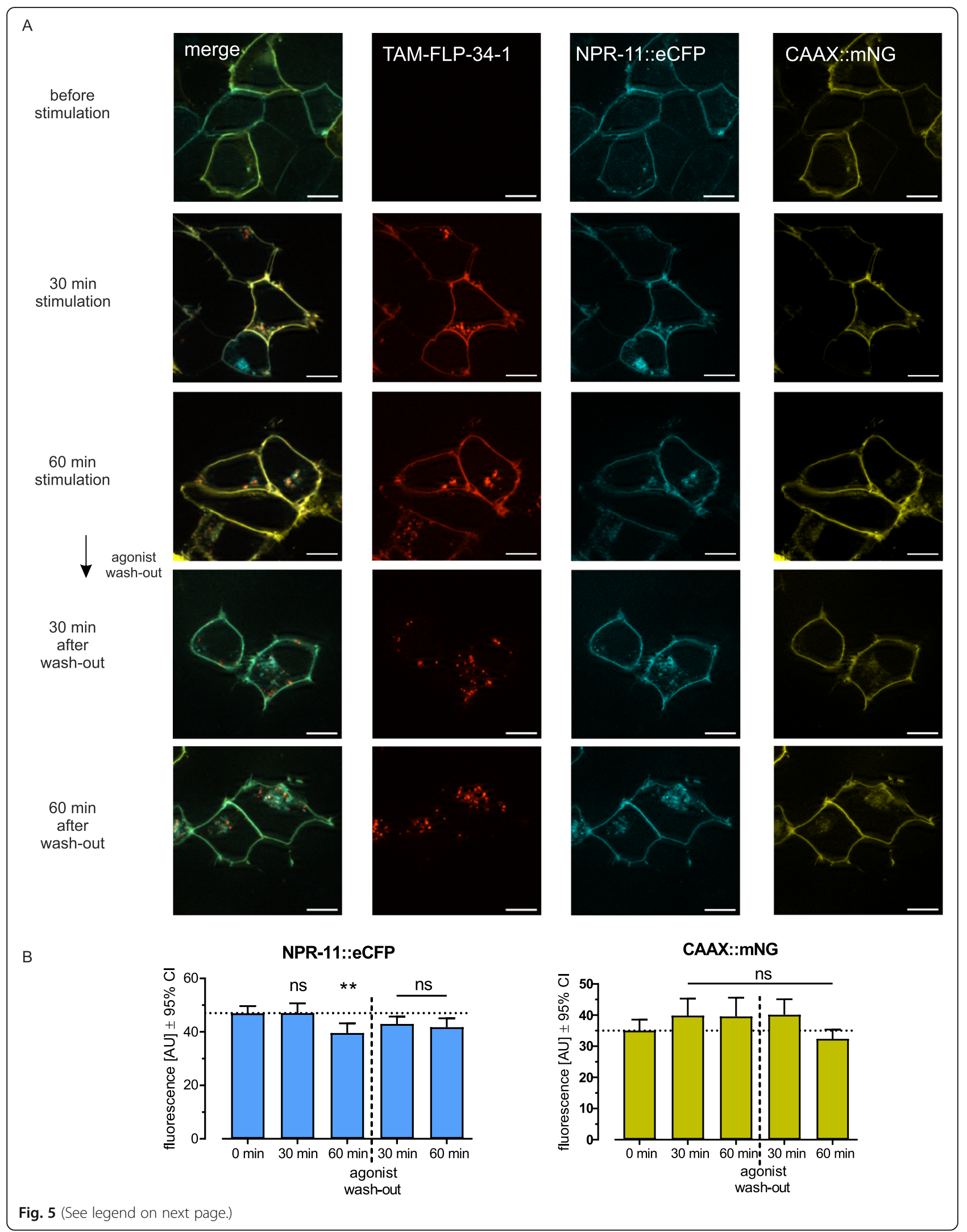


(See figure on previous page.)

Fig. 5 Enhanced bystander BRET in vitro shows potential NPR-11 internalization. A NPR-11 might undergo agonist-promoted endocytosis in vitro while the membrane marker remains at the plasma mebrane. A genetic fusion of NPR-11 with a cyan fluorescent protein (eCFP) and a mNeonGreen anchored to the plasma membrane via the CAAX motif was expressed heterologously in HEK293 cells. Cells were stimulated with 100 nM TAM-FLP-34-1, subcellular localization was monitored in live cells after $30 \mathrm{~min}, 60 \mathrm{~min}$, and additionally $30 \mathrm{~min}$ and 60 min after agonist wash-out. Cell nuclei were stained with Hoechst33342. B Membrane fluorescence measurement ( $x$-fold of before stimulation) of NPR-11::eCFP (left panel) and CAAX::mNG (right panel) before stimulation, $30 \mathrm{~min}$ and $60 \mathrm{~min}$ before and after agonist wash-out with cells treated as described in A. While the fluorescence of CAAX::mNG remains stable over time, the fluorescence of NPR-11::eCFP drops significantly after 60 min of stimulation suggesting peptide-mediated internalization. Fluorescence levels recover after agonist wash-out. Shown is the mean \pm SEM in $n=3$ assays with $N \geq 10$ cells per condition. ${ }^{*} p \leq 0.05$, one-way ANOVA, Dunnett's post test against 0 min. Scale bars $=10 \mu m$

receptor (Fig. S5). Meanwhile, co-expression of NRP-11:: eYFP with rab11::eCFP, a recycling endosomes marker protein [38], showed a strong overlap, in particular after agonist wash-out (Fig. 6). This led us to the conclusion that NPR-11 indeed internalized and might undergo a recycling process rather than a degradation in lysosomes (Fig. 6, Fig. S5). To conclude, we generated an enhanced bystander BRET between a cell membrane marker and the Nluc-fused receptor in C. elegans, forming the basis for studying subcellular protein localization and proteinprotein proximity in vivo. Combining in vitro and in vivo results, we suggest that NPR-11 is internalized after activation, supported by the lowering BRET and fluorescent microscopy while it is rather recycled than

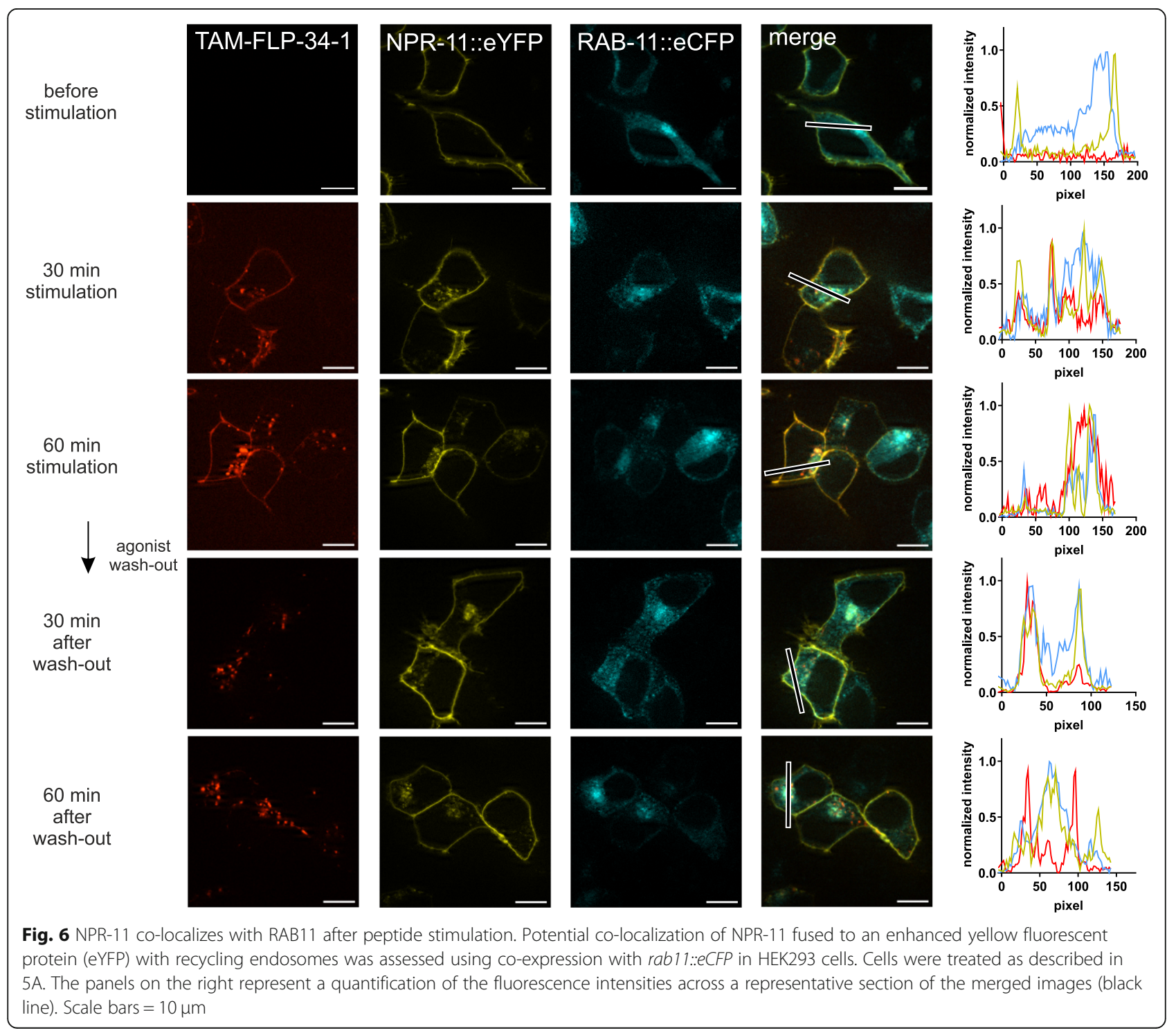


degraded (co-localization with recycling endosomes more clearly than with lysosomes) and transported back to the membrane (increasing BRET after $70 \mathrm{~min}$, schematic in Fig. 7).

\section{Discussion and conclusions}

NanoBRET has become an indispensable tool for studying protein-protein interactions, ligand-receptor binding properties, protein trafficking, and protein localization in vitro. It yields reliable data and due to its successful application in various scientific areas, variations of BRET adapted for ex vivo studies are constantly emerging (summarized in [13]). Compared to single cells or complex model organisms such as mice, C. elegans' major advantage is that molecular processes can be investigated in the natural environment of proteins at a decent spatial and temporal resolution. Here, we generated specific NanoBRET sensors and established NanoBRET as a proof-of-concept for the use in the nematode C. elegans. We applied the method as a tool for investigating ligand-receptor interactions and highlighted that it can be adapted to different applications such as an enhanced bystander version for the study of protein trafficking in real time within a cell in the context of an entire organism. We also showed that the technique does have limitations and that careful considerations regarding the investigated interactions need to be taken.

To date, the two most considerable limitations hampering the use of NanoBRET for applications in vivo are the bioavailability of the substrate $[21,39]$ and the low penetrance of luminescence through tissue [33]. The small and translucent nature of $C$. elegans makes the

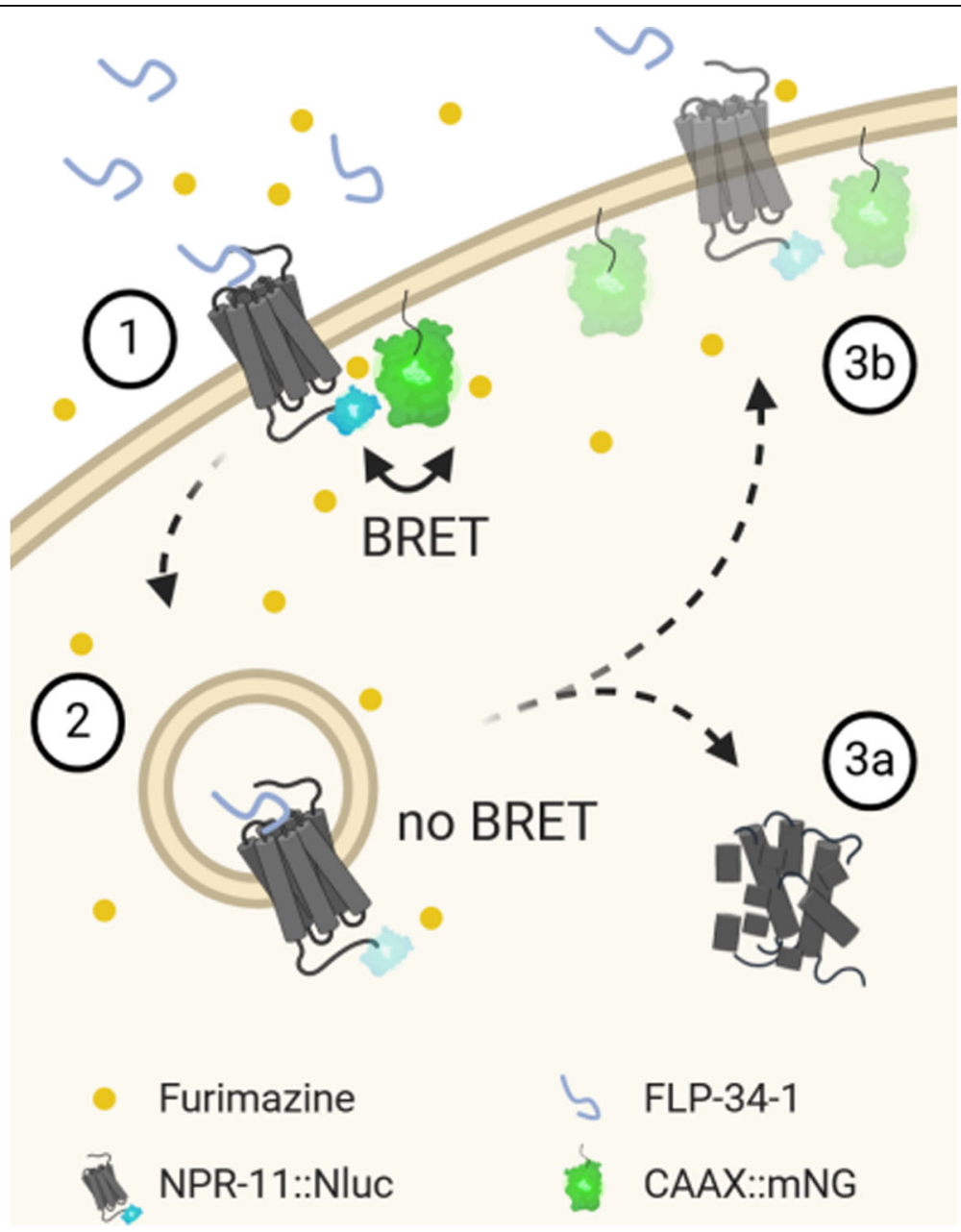

Fig. 7 Scheme of potential receptor internalisation tracked with enhanced bystander BRET. 1 The energy donor (Nluc C-terminally fused to NPR11) generates a bystander BRET with an energy acceptor ( $m$ NeonGreen fused to the CAAX box of let-60) located at the inner membrane upon furimazine application. In the presence of the agonist (FLP-34-1), the receptor undergoes endocytosis (2), lowering the number of available donor molecules at the membrane that are able to transfer energy to the acceptor. This effect shifts the ratio of luminescence and fluorescence and subsequently, yields a lower BRET window. The receptor is then either degraded in lysosomes (3a) or recycled in recycling-endosomes and transported back to the membrane. The latter one increases the bystander BRET again due to the close proximity of donor and acceptor (3b). Image created with BioRender.com 
nematode an ideal organism compared to other models to overcome these obstacles and promising studies have already reported the detection of luminescence signals in living nematodes when using the firefly luciferase/luciferin system [40-42]. In line with these studies, our data identified three parameters essential for reliably measuring luminescence in nematodes: $i$ ) careful selection of the substrate and the corresponding luciferase, ii) preparation of the animals, and iii) expression level of the protein fused to the luciferase. As the firefly luciferase/ luciferin system is dependent on ATP and less bright than the Nluc/coelenterazine $\mathrm{H}$ or furimazine system, we chose the latter one for BRET analyses and furimazine as substrate due to its stability. With the set-up devised in this study, even luminescence of Nluc-fusion proteins that are present at low levels, such as NPR-11, can be detected. This was facilitated by making a small incision in the worms, which strongly increased luminescence, probably because it improves the limited bioavailability of furimazine $[21,39]$. It has to be noted that due to the necessary incision of the worm, long-term studies are not possible as this incision might change the physiology and leads to premature death of the worms.

While NPR-11 is present only in a few neurons [28], the other receptor used in our study, lat-1, is expressed in several tissues (neurons, intestine, muscles, reproductive system [30, 43-45]), rendering much stronger luminescence signals in the respective Nluc::lat-1 worm strain. Thus, it can be speculated that Nluc-fusion proteins that express at higher levels or abundantly, might even generate sufficient luminescence to create NanoBRET in intact worms of fewer number. It has to be noted that to increase the amount of Nluc-fused protein, we chose to use extrachromosomal expression of constructs rather than single copy integration. However, it is conceivable that single copy integrated constructs can also be detected as long as expression is sufficient.

Despite the promising feasibility of measuring luminescence and NanoBRET in C. elegans, the experimental set-up can be still improved. For instance, analyses of single worms are hardly possible as well as long-term studies since nematodes harmed by incisions die after a short time as mentioned above.

For assaying peptide-binding of cell surface receptors in C. elegans in real time, NanoBRET is a highly suitable tool. The comparison of in vivo NanoBRET with the in vitro method showed similar characteristics of the ligand-receptor binding (Fig. 3, Fig. S3). Especially for high affinity peptide-receptor interactions $\left(K_{d}<1 \mu \mathrm{M}\right)$ as it is the case for FLP-34-1 binding to NPR-11, this proved to be true. The affinity of TAM-FLP-34-1 to the receptor is similar in both settings. The slightly higher $\mathrm{K}_{\mathrm{d}}$ value in vivo (in vivo: $1.4 \mu \mathrm{M}$; in vitro: $388 \mathrm{nM}$ ) is presumably caused by differences in the effective peptide concentration directly at the receptor compared to the concentration initially applied to the medium. While in vitro, the peptide concentration in the medium roughly equals the concentration at the receptor, in vivo the amount of peptide reaching the receptors in the worm is most likely much lower than the initial concentration due to penetration issues. Further, the peptide amount present at NPR-11 in the nematode can be reduced as other neuropeptide receptors might be capable of sequestering the ligand (specifically as well as nonspecifically) [23]. Thus, NanoBRET in vivo offers the possibility to specifically evaluate ligand-binding selectivity in a distinct tissue in the context of surrounding tissues taking aspects such as unspecific binding into consideration. Due to the clustering of different proteins in one cell, it is likely that even the scrambled peptide binds structures that are in close proximity to the Nluc, generating a certain unspecific BRET. Interestingly, the BRET windows of the in vivo measurements appear to be generally smaller that the in vitro ones (Fig. 3, Fig. S3) despite the use of the same BRET sensors and analysis filters. This effect is probably caused by the different light absorption and scattering conditions in the worm compared to single cells.

In contrast to FLP-34-1/NPR-11, the pair tethered agonist peptide/LAT-1 represents low-affinity binding. The scrambled control peptide TAM-scrpLAT-1, which does not activate the receptor (Fig. S3), still yields a BRET signal (Fig. 3). We hypothesize that the reason for this is the same as for the scrambled peptide of NPR-11, but to a stronger extent: In the environment of the cellular context, in which numerous different proteins are present, transient interactions of a peptide are likely to occur in the proximity of the receptor and may be unspecific. Thus, in this case, it cannot be determined beyond doubt that the BRET signal generated by TAM-pLAT-1 is specific and just not saturated at $10 \mu \mathrm{M}$, highlighting that in cases of low-affinity interactions, BRET might be not a technique of choice. However, functional analyses show that this peptide reliably activates LAT-1 (Fig. S3) [31]. Since the tethered agonist is normally directly integrated within LAT-1, low-affinity binding is sufficient for activation. This has also been shown for other Adhesion GPCR [32]. Our data show that ligand-receptor NanoBRET in vivo is a valuable tool but results need careful evaluation when studying low-affinity interactions.

It is conceivable that this in vivo NanoBRET proof-ofconcept set-up can be adapted for numerous applications besides ligand-receptor interactions. Of great interest are also questions related to general protein-protein interactions and protein dimerization. The existing techniques to address these questions include analytical 
ultracentrifugation (reviewed in [46]), light scattering (summarized in [47]), and NanoBit (summarized in [48]). Some methods are already established in C. elegans such as fluorescence resonance energy transfer (FRET) [49, 50] and bimolecular fluorescence complementation (BiFC) $[51,52]$. In case of the latter two, which both have been proven to be valuable and widely used techniques, protein(s) of interest are fused to fluorescent proteins or parts of them and in case of an interaction, a specific fluorescence is detected. One advantage of NanoBRET over BiFC and FRET is that no excitation with laser light is necessary and, therefore, the fluorescent background is minimized. Further, BRET offers the general possibility to measure many samples in 'medium-throughput' in 384-well plates in plate readers, which significantly increases throughput and facilitates handling compared to FRET experiments, which typically use microscopy.

Besides the NanoBRET technique for ligand-receptor interactions, an approach for in vivo enhanced bystander NanoBRET was established in this study yielding promising insights into protein trafficking. The cellular localization of proteins, in particular cell surface receptors, is of high interest for pharmacological interventions. For instance, in the case of GPCRs, receptor signaling from the cell membrane often is the desired pharmacologically active pathway and receptor internalization goes along with receptor desensitization. In other cases such as drug shuttling into a target cell, receptor internalization is desired, or specific signaling responses are triggered from intracellular compartments (e.g. [53, 54]).

With the CAAX::mNG we devised and employed a NanoBRET sensor for labelling the cell membrane, which can be used as a universal tool for NanoBRET assays in combination with different proteins. Our data based on this sensor showed that NPR-11 is present at the cell membrane, but the NanoBRET signal decreased after receptor activation in vivo. This indicates a removal of the GPCR from the membrane, most probably by internalization. In vitro analyses using markers for membrane, endosomes and lysosome confirmed this hypothesis. This is further supported by the fact that the CAAX:: mNG signal remains stable over time indicating that the protein persists at the membrane (Fig. 5, Fig. S5). Internalization is a well-established concept of mammalian NPY receptors (summarized in [55]). We now extend this knowledge to show that also the distant $C$. elegans homo$\log$ NPR-11 undergoes receptor internalization. Hence, the concept of internalization is transferable to C. elegans. This is a novel finding in the context of the nematode's GPCR biology. Furthermore, the enhanced bystander BRET measurements proved as a suitable tool for studying this aspect of receptor trafficking. Due to the existence of numerous fluorescent proteins suitable for expression in C. elegans, it might be possible to generate a two-step enhanced bystander NanoBRET by tagging two cell compartments with different fluorescent proteins (e.g. membrane and recycling endosomes), which provide a distinguishable spectrum and monitor trafficking of Nlucfused proteins between different compartments by measuring specific fluorescent signals with a spatial and temporal resolution.

One difficulty of in vivo NanoBRET is to track changes of proteins within the organism as most molecular processes are in steady-state. Specific interactions need a trigger such as ligand-binding to change the equilibrium. Since the components of NanoBRET are mostly proteins, expression can be regulated easily in C. elegans. Combining NanoBRET with knockout strains and systems enabling controllable protein expression (for instance through heat-shock promoters [56], the Q system [57], and the auxin-inducible system [58]) offers numerous possibilities of real-time tracking protein interactions and dynamics in vivo. In the light of the promising applications of NanoBRET in C. elegans, careful evaluation of each set up needs to be taken as the success of NanoBRET depends on the tissue of interest, the subcellular localization of the proteins to be investigated and thus, their accessibility. It also has to be noted that the technique in its current state is not intended to be suitable for high-throughput screenings of interactions, but rather to test distinct interactions and their impact. The tremendous potential of the technique and the extent of its application for intracellular proteins remain to be determined in the future.

\section{Methods}

\section{Materials and reagents - sources}

All standard chemicals were from Sigma Aldrich, ThermoFisher Scientific or Carl Roth GmbH unless stated otherwise. All enzymes were obtained from New England Biolabs. The following reagents, bacterial strains, cell lines and resources were used and respective sources listed:

\begin{tabular}{lll}
\hline $\begin{array}{l}\text { REAGENT or } \\
\text { RESOURCE }\end{array}$ & SOURCE & IDENTIFIER \\
\hline $\begin{array}{l}\text { Bacterial and Virus Strains } \\
\text { E. coli DH5a }\end{array}$ & $\begin{array}{l}\text { ThermoFisher } \\
\text { Scientific }\end{array}$ & $18,258,012$ \\
$\begin{array}{l}\text { E. coli OP50 } \\
\text { E. coli SW106 }\end{array}$ & N/A \\
$\begin{array}{l}\text { Biological Samples } \\
\text { C. elegans cDNA }\end{array}$ & N/A \\
$\begin{array}{l}\text { Chemicals } \\
\text { Forskolin }\end{array}$ & This study & \\
Sodium azide & Sigma-Aldrich & CAS \\
Hoechst33342 & Roth & $66575-29-9$ \\
CAS
\end{tabular}


Materials and reagents - sources (Continued)

\begin{tabular}{|c|c|c|}
\hline $\begin{array}{l}\text { REAGENT or } \\
\text { RESOURCE }\end{array}$ & SOURCE & IDENTIFIER \\
\hline & & $23491-52-3$ \\
\hline DMSO & Sigma-Aldrich & $\begin{array}{l}\text { CAS 67-68- } \\
5\end{array}$ \\
\hline Lipofectamine 2000 & ThermoFisher & \#11668019 \\
\hline Trypsin & ThermoFisher & \#25300054 \\
\hline HBSS & ThermoFisher & \#15356878 \\
\hline HEPES & ThermoFisher & \#15630080 \\
\hline MetafectenePro & Biontex & \#T040 \\
\hline Coelenterazine $\mathrm{H}$ & Prolume/Nanolight & $\begin{array}{l}\text { CAS } \\
50909-86-9\end{array}$ \\
\hline $\begin{array}{l}\text { LysoTracker } \\
\text { Blue DND-22 }\end{array}$ & ThermoFisher & \#L7525 \\
\hline \multicolumn{3}{|l|}{ Peptides } \\
\hline Peptides & This paper & N/A \\
\hline \multicolumn{3}{|l|}{ Critical Commercial Assays } \\
\hline $\begin{array}{l}\text { pGL4.29[luc2P/Hygro/CRE] reporter } \\
\text { gene plasmid }\end{array}$ & Promega & \#Е8471 \\
\hline ONE-Glo Luciferase Assay System & Promega & \#E6120 \\
\hline Nano-Glo ${ }^{\circledR}$ Live Cell Assay System & Promega & \#N2011 \\
\hline AlphaScreen cAMP Detection Kit & PerkinElmer & $6760635 D$ \\
\hline \multicolumn{3}{|l|}{$\begin{array}{l}\text { Experimental Models: } \\
\text { Cell Lines }\end{array}$} \\
\hline HEK293 & $\begin{array}{l}\text { German Collection of } \\
\text { Microorganisms and } \\
\text { Cell Cultures (DSMZ) }\end{array}$ & ACC 305 \\
\hline $\cos -7$ & $\begin{array}{l}\text { German Collection of } \\
\text { Microorganisms and } \\
\text { Cell Cultures (DSMZ) }\end{array}$ & ACC 60 \\
\hline \multicolumn{3}{|l|}{$\begin{array}{l}\text { Experimental Models: } \\
\text { Organisms/Strains }\end{array}$} \\
\hline $\begin{array}{l}\text { Caenorhabditis elegans } \\
\text { strains, see Table S3 }\end{array}$ & This paper & N/A \\
\hline \multicolumn{3}{|l|}{ Oligonucleotides } \\
\hline Primers, see Table S2 & SeqLab & N/A \\
\hline \multicolumn{3}{|l|}{ Scientific instruments } \\
\hline Plate reader & PerkinElmer/ Tecan & \\
\hline Micro injector & Eppendorf & \\
\hline DMi8 confocal microscope & Leica & \\
\hline Axiovert Observer Z1 microscope & Zeiss & \\
\hline
\end{tabular}

\section{Peptide synthesis}

Peptides were synthesized by solid-phase peptide synthesis (SPPS) using a Syro II peptide synthesizer (MultiSynTech; resins and amino acid from Iris Biotech) in $15 \mu \mathrm{mol}$ scale, following the 9-fluorenylmethoxycarbonyl/tert-butyl $(\mathrm{Fmoc} / \mathrm{tBu})$ strategy (reviewed in [59]). Briefly, the peptide sequence is built up from $\mathrm{C}$ to $\mathrm{N}$ terminus on an immobilized solid-phase as a growing peptide chain by repeated steps of coupling N-terminally Fmoc protected amino acid derivatives, and deprotection of the $\mathrm{N}$-terminal Fmoc group to enable the coupling of the next amino acid. Control peptides were generated by scrambling of the peptide sequence and synthesized in parallel. Peptides were cleaved from the resin by incubation with trifluoroacetic acid (TFA) $/ \mathrm{H}_{2} \mathrm{O} /$ triisopropylsilane $(90 / 5 / 5, \mathrm{v} / \mathrm{v} / \mathrm{v})$, which simultaneously removes the side chain protection groups from reactive side chains. All peptides were purified to $\geq 95 \%$ homogeneity by preparative HPLC (Shimadzu) using a Phenomenex Aeris, $100 \AA$ (C18) column and linear gradients of solvent $\mathrm{B}$ (acetonitrile+ $0.08 \%$ trifluoroacetic acid) in $\mathrm{A}\left(\mathrm{H}_{2} \mathrm{O}+0.1 \%\right.$ trifluoroacetic acid). The identity of the peptides was confirmed by MALDI-ToF mass spectrometry (Ultraflex III MALDI ToF/ToF, Bruker, Billerica, USA).

To generate the amidated C terminus of FLP-34-1, a TentaGel R RAM resin (Iris Biotech) was used as solid phase. For a fluorescent variant of FLP-34-1, 5(6)-carboxytetramethylrhodamine (TAM) was coupled to the free $\mathrm{N}$-terminus using 2 eq each of the fluorescent dye, diisopropylethylamine (DIEA), and 1.9 eq. 1-[Bis (dimethylamino)methylene]-1H-1,2,3-triazolo[4,5-b] pyridinium 3oxide hexafluorophosphate (HATU) in dimethylformamide (DMF) at room temperature overnight in the dark. Peptides were then further cleaved from the resin and purified as described above.

LAT-1 peptides (wild-type and scrambled sequence) were fluorescently labeled at the $\mathrm{C}$ terminus. For that purpose, $15 \mu \mathrm{mol}$ TentaGel S HMP resin (Iris Biotech) was loaded with $\mathrm{N} \alpha$-protected 2,3-diaminoproprionic acid with an orthogonally protected side chain (Fmoc-Dap (Dde)-OH). After automated elongation of the peptide sequence up to the $\mathrm{N}$ terminus, Dap (Dde) was selectively deprotected on resin by repeated addition of $2 \%$ hydrazine $(\mathrm{v} / \mathrm{v})$ in DMF $(10 \times 10 \mathrm{~min})$, and coupled to a TAM-fluorophore as described above. For non-fluorescent peptide variants, the liberated Dap side chain was acetylated on resin using 10 eq of acetic anhydride $\left(\mathrm{Ac}_{2} \mathrm{O}\right)$ and DIEA in dichloromethane (DCM) at room temperature for $15 \mathrm{~min}$. Peptides were further cleaved from the resin and purified as described above.

\section{C. elegans lysis}

10 adult wild-type hermaphrodites were transferred into lysis buffer (1x PCR buffer, $2 \mu \mathrm{g} / \mathrm{ml}$ proteinase $\mathrm{K}$ ), once freeze cracked at $-80^{\circ} \mathrm{C}$ for $5 \mathrm{~min}$ and lysed at $60^{\circ} \mathrm{C}$ for 45 min. Proteinase $\mathrm{K}$ was inactivated at $90^{\circ} \mathrm{C}$ for $15 \mathrm{~min}$ and the mixture was used as DNA template for PCR reactions.

\section{Generation of constructs NPR-11 constructs fused to a nanoluciferase}

Npr-11p::Nluc::npr-11 and npr-11p::Nluc::npr-11::gfp For expressing a variant of the nanoluciferase (Nluc, 
Promega, USA), fused to the $\mathrm{N}$ terminus of $n p r-11,3 \mathrm{~kb}$ upstream of $n p r-11$ was amplified from fosmid WRM0616cB05 with primer pnpr-11_SbfI_f and pnpr11_XbaI_r attaching Sbfl and XbaI restriction sites. The fragment was cloned into two modified pPD95.79 (from A. Fire, Addgene plasmid \#1496) expression vectors, one with and one without a GFP, using Sbfl and XbaI. npr$11 \mathrm{cDNA}$ was purchased from GenScript and amplified with npr-11_nluc_f and npr-11_XmaI_r/ npr-11_XmaI_ GFP_r (for sequences see Table S2) generating an overlap to the Nluc at the $5^{\prime}$ end and an XmaI restriction site at the 3' end. The Nluc with an additional SGGGGS linker at the 3' end was amplified from pNL1.3_secNluc plasmid (Promega, USA) with primers Nluc_XbaI_f and Nluc_NPR-11_r generating an XbaI restriction site at 5' and an overlap to $n p r-11$ at the $3^{\prime}$ end. The Nluc and $n$ pr-11 fragments were fused together by overlap PCR and inserted into the modified pPD95.79 with pnpr-11 using XbaI and XmaI restriction sides (pSP167 with GFP, pSP168 without GFP). Primer sequences are shown in Table S2.

Npr-11p::npr-11::Nluc For studying intracellular BRET, the Nanoluciferase (Nluc,Promega, USA) was fused to the $\mathrm{C}$ terminus of $n p r-11$. cDNA of $n p r-11$ was amplified with XbaI_npr-11_f/npr-11_Nluc_r from pSP168 inserting an $\mathrm{XbaI}$ restriction site at the $5^{\prime}$ end and parts of a SGGGGS linker at the $3^{\prime}$ end. The Nluc was amplified from pNL1.3_secNluc plasmid (Promega, USA) using Nluc_Linker_npr-11_f/Nluc_XmaI_r to add a 5' SGGGGS Linker and an XmaI restriction site at the $3^{\prime}$ end. Both fragments were fused together via overlap PCR and inserted into a modified pPD95.79 containing $3 \mathrm{~kb}$ upstream of $n p r-11$ (generated as described above) using $X b a \mathrm{I}$ and $X m a \mathrm{I}$ restriction sites resulting in pSP185. Primer sequences are shown in Table S2.

\section{Npr-11 constructs for in vitro analysis}

For cAMP reporter gene assays, a plasmid was used containing the cDNA of $n p r-11$ fused C-terminally to the enhanced yellow fluorescent protein (eYFP) in the pVitro2-hygro-mcs vector (InvivoGen) generated previously [23]. An $n p r-11$ fused to eCFP used for imaging was generated from this construct by PCR-overlap extension, using the primers pVitro_prolong_for and NPR11-Linker_rev to amplify the NPR-11 part, while eCFP was amplified from Y1-eCFP_N1 [60] using the primers Linker-eCFP_for and N1_rev. The genetic fusion npr-11:eCFP was then ligated into the pVitro2 vector using the restriction enzymes EcoRV and $X b a \mathrm{I}$ (all enyzmes from ThermoFisher). The cDNA of the membrane marker CAAX::mNG was cloned from the expression plasmid containing synthetic introns (see below) using PCR overlap extension with the primers HindIII_
Kozak_mNG_part1_for, mNG_part1_rev, mNG_part2 for, mNG_part2_rev, mNG_part3_for, mNG_part3_rev, mNG_part4-Li-CAAX_for, mNG_part4-CAAX_NotI_ XhoI_XbaI-rev, and sub-cloned into an empty pcDNA3 vector using HindIII and XbaI.

For NanoBRET binding assays, the nanoluciferase (Nluc, Promega, USA) was genetically fused to the $\mathrm{N}$ terminus of $n p r-11$, spaced by a SGGGGS linker as previously described [35]. To facilitate expression and targeting to the plasma membrane, the Nluc sequence was preceded by a secretion signal derived from human IL-6 as previously described (secNluc [5];). The Nluc sequence was amplified from the pNL1.3_secNluc plasmid (Promega, USA).

\section{Rpl-28p::mNeonGreen::CAAX}

For a stable mNeonGreen (mNG) localization in all somatic cells on the inner plasma membrane, mNG was fused to the CAAX motif of C. elegans let-60 separated by a DNA linker. The linker (amino acid sequence: GSAGTMASNNTASG) and the CAAX sequence (amino acid sequence: KPQKKKKCQIM*) were added to $\mathrm{mNG}$ amplified from vector pDD346 (from D. Dickinson, Addgene plasmid \#133311) by three subsequent overlap PCR with following primers: $\mathrm{mNG}_{\text {_ }}$ XmaI_f (1. - 3.), mNG_CAAX_1_r (1.), mNG_CAAX_2 r (2.) and mNG_CAAX_3_EcoRI_r (3.) attaching unique restriction sides for XmaI and EcoRI. The resulting construct was cloned upstream of a 1500 bp sequence $5^{\prime}$ of $r p l-28$ amplified from pGC185 [61] with primers rpl28_SbfI_f and rpl-28_XmaI_r into pPD95.79 with Sbfl and XmaI yielding plasmid pSP177. For primer sequences see Table S2.

Lat-1p::lat-1(1-249)::Nluc::lat-1(250-650)::GFP::Iat-1(651-1015)

The Nluc was inserted into LAT-1 between the hormone-binding and the GPCR autoproteolysisinducing domain (GAIN) after amino acid position 249 into vector pSP5 [30], which contains the genomic sequence of lat-1 with the $7 \mathrm{~kb}$ promoter sequence, using recombineering [62]. A recombineering targeting cassette consisting of three parts - a kanamycin resistance gene, the first seven amino acids of the lat- 1 exon 5 and the Nluc - was generated. For this purpose, five different fragments were amplified and fused together using an overlap PCR resulting in construct lat-1(1)::kanR::lat1(2)::Nluc::lat-1(3). Primer pairs were the following: lat1_1_f and lat-1_1_r for lat-1(1), kanR_f and kanR_f for the kanamycin resistance cassette, lat-1_2_f and lat-1_2_ r for lat-1(2), lat-1_Nluc_f and lat-1_Nluc_r for the Nluc, and lat-1_3_f and lat-1_3_r for lat-1(3). Primer sequences are listed in Table S2. pSP5 was transformed together with the respective fragment into electrocompetent E. coli SW106 cells expressing $\lambda$ Red genes 
that promote homologous recombination [62]. Positive cells were selected via kanamycin resistance yielding plasmid pSP181.

\section{C. elegans strains}

C. elegans strains were maintained as described in [63]. All strains used in this study are listed in Table S3. Some strains were provided by the CGC, which is funded by $\mathrm{NIH}$ Office of Research Infrastructure Programs (P40 OD010440).

\section{Generation of transgenic $C$. elegans strains}

All transgenic strains expressed a stable extrachromosomal array. Those strains were obtained by microinjection of plasmid DNA into the syncytial gonad of young adult hermaphrodites according to $[64,65]$. The injection mix contained the DNA of interest $(10 \mathrm{ng} / \mu \mathrm{l}$ for plasmids encoding $n p r-11 ; 1 \mathrm{ng} / \mu \mathrm{l}$ for plasmids encoding lat-1), a plasmid carrying a selection marker (pRF4 (rol-6 (su1006)): $100 \mathrm{ng} / \mu \mathrm{l}$ [65]; IR98 (hygromycin resistance): $30 \mathrm{ng} / \mu \mathrm{l}[66])$ and was filled up with pBluescript II SK+ vector DNA (Stratagene) as stuffer DNA to achieve a final concentration of $120 \mathrm{ng} / \mu \mathrm{l}$. After injection, the worms were left to regenerate at $15^{\circ} \mathrm{C}$ for three days and positive progeny was selected. For selection for hygromycin B resistance, worms were kept on NGM plates containing $0.3 \mathrm{mg} / \mathrm{ml}$ hygromycin B. F2 individuals stably expressing the co-injection marker were established as line.

\section{Preparation of C. elegans for luminescence detection and BRET measurements}

All measurements were conducted using synchronized young adult worms (1 day post L4). Individuals were washed twice with HBSS (Hanks' balanced salt solution with $25 \mathrm{mM}$ HEPES, $\mathrm{pH} 7.4,37^{\circ} \mathrm{C}$ ) and the number of worms/ $\mu$ l was calculated.

For luminescence measurements of intact worms, animals $(1 ; 10 ; 50 ; 100$ or 500$)$ were directly transferred into the wells of a white flat-bottom 384-well plate in $50 \mu \mathrm{l}$ HBSS buffer. Worms to be cut were pre-washed with M9+0.1\% Tween to avoid sticking of worms to the dish and subsequently transferred in $2 \mathrm{ml}$ of HBSS. Incisions were made in the middle of the body with a scalpel blade and worms were immediately afterwards transferred with a glass pipette into HBSS buffer on ice. For mechanically cracking, a worm suspension was homogenized in tubes with $150 \mu \mathrm{l}$ HBSS and six glass beads $(\varnothing=3 \mathrm{~mm})$ using with a Precellys homogenizer (Bertin instruments, France) for $40 \mathrm{~s}$ at $5000 \mathrm{rpm}$. Samples were placed on ice until further usage.

\section{Luminescence detection}

50 prepared worms were transferred into a white flat bottom 384-well plate in a total volume of $50 \mu \mathrm{l} \mathrm{HBSS}+$
25 mM HEPES (pH 7.4; denoted BRET buffer). Immediately after adding coelenterazine $\mathrm{H}$ solution (Nanolight/ Prolume, USA) to a final concentration of $4 \mu \mathrm{M}$, luminescence was detected using an EnVision plate reader (PerkinElmer, USA) and a NanoBRET Blue 460/80 nm filter with $1000 \mathrm{~ms}$ integration time (five repeats every 5 min for long time observation).

\section{In vivo bioluminescence energy transfer (BRET) binding assay}

For BRET binding assays in vivo, the nanoluciferase (Nluc) was applied as energy donor and either peptides labeled with the TAM fluorophore or the mNeonGreen fluorescent protein fused to a receptor served as acceptor.

The peptide-receptor binding BRET was conducted with TAM-FLP-34-1/TAM-pLAT-1 and their corresponding scrambled versions dissolved in $\mathrm{H}_{2} \mathrm{O}+0.5 \%$ BSA and 5\% DMSO. 30 Nluc-expressing worms with incisions in $50 \mu \mathrm{l}$ BRET buffer were incubated with dissolving buffer or peptide solutions of final concentrations ranging from $0.05-10 \mu \mathrm{M}$ in a 384-well plate. During a $25 \mathrm{~min}$ incubation with gentle shaking, $10 \mu \mathrm{l}$ Nano-Glo Live Cell Reagent (N2011, Promega, USA) of a $5 \mathrm{x}$ stock were added according to manufacturer's instructions after $15 \mathrm{~min}$ to each well. Competition-binding assays were performed similarly, but additionally, unlabeled peptide (final concentrations $0.016-10 \mu \mathrm{M})$ was pipetted into each well and $5 \mu \mathrm{l}$ of a 10x stock Nano-Glo Live cell reagent was applied after 15 min.

The $K_{i}$ of FLP-34-1 was calculated defining TAMFLP-34-1 as 'hot' ligand with $\mathrm{c}=1.6 \mu \mathrm{M}$ and $\mathrm{K}_{\mathrm{d}}=1.5 \mu \mathrm{M}$ with a one-site fit $K_{i}$ with GraphPad Prism version 6 (GraphPad Software).

Luminescence (L) and fluorescence (F) were detected with a microplate plate reader (Tecan Spark) using the following filter set: donor $=430-470 \mathrm{~nm}$, acceptor $=550$ $700 \mathrm{~nm}$ with $1000 \mathrm{~ms}$ integration time. BRET was calculated by dividing $\mathrm{F}$ values by $\mathrm{L}$ values. For each experiment, the background signal of donor-only cells was subtracted, such that the BRET ratio at $0 \mu \mathrm{M}$ ligand equals 0.00. In Fig. 3B (left) and Fig. 3D, the mean of $n=4$ (NPR11) or $n=3$ (LAT-1) independent, individually background-corrected single experiments is presented. The netBRET presented in Fig. 3B (right) is calculated by subtracting the averaged, baseline-corrected values of the scrambled control from the averaged, baseline-corrected BRET values of the active peptide. The $K_{d}$ value of TAMFLP-34-1 in vivo was calculated using GraphPad Prism 6 version (GraphPad Software) with a one-site total and nonspecific binding fit.

Luminescence levels depended on the used strain, reaching (without ligand) approximately $2000 \mathrm{AU}$ in 
Nluc::npr-11 animals and up to 32,000 AU in Nluc::lat-1 expressing worms. For enhanced bystander BRET analyses, 30 cut worms (APR716 and APR718) in $50 \mu \mathrm{l}$ HBSS buffer were incubated for 10 min with $10 \mu \mathrm{l}$ of Nano-Glo Live Cell Reagent (5x stock). Luminescence and fluorescence were measured once prior to peptide stimulation. Afterwards, FLP-34-1 (final concentration $5 \mu \mathrm{M})$ or $\mathrm{H}_{2} \mathrm{O}$ with $0.5 \%$ BSA and $2.5 \%$ DMSO as control were added to each well and luminescence and fluorescence was measured over the course of $80 \mathrm{~min}$. The acceptor filter for this setting was altered to 505$605 \mathrm{~nm}$, while the donor filter remained at $430-470 \mathrm{~nm}$, as before.

\section{In vitro bioluminescence energy transfer (BRET) binding assay}

The binding of TAM-FLP-34-1 and its scrambled analog was also tested in vitro using membranes of transfected HEK293 cells as described previously [35]. Briefly, membranes of HEK293 cells transiently transfected with Nluc::NPR-11::eYFP were prepared analogously to a described protocol $[67,68]$. TAM-labeled peptide in a concentration range of $10^{-12} \mathrm{M}$ to $10^{-5} \mathrm{M}$ was incubated with the membranes containing $0.5 \mu \mathrm{g}$ total protein in $90 \mu \mathrm{l}$ BRET buffer containing $0.1 \%$ bovine serum albumin and Pefabloc SC in solid black 96 well plates for 10 min under gentle agitation at room temperature. Directly before the measurements, coelenterazine $\mathrm{H}$ in BRET buffer (10x stock solution) was added to a final concentration of $4 \mu \mathrm{M}$, and BRET was measured in a microplate reader (Tecan Spark) with the following filter settings: luminescence (L) $430-470 \mathrm{~nm}$, fluorescence $(\mathrm{F})$ $550-700 \mathrm{~nm}$. The BRET ratio was calculated by the ratio of $\mathrm{F} / \mathrm{L}$. The $\mathrm{K}_{\mathrm{d}}$ values were obtained from a threeparameter logistic fit in GraphPad Prism version 5.03 (GraphPad Software).

\section{Cell culture}

All in vitro experiments were carried out using either HEK293 cells (Homo sapiens, embryonic kidney, DSMZ (German Collection of Microorganisms and Cell Cultures) ACC 305) or COS-7 cells (African green monkey, cercopithecus aethiops, kidney, DSMZ (German Collection of Microorganisms and Cell Cultures) ACC 60). HEK293 cells were kept in Dulbecco's Modified Eagle's Medium (DMEM) with Ham's F-12 (v/v) and 15\% (v/v) heat-inactivated fetal calf serum (FCS), while COS-7 cells were cultured in DMEM with 10\% (v/v) FCS and $1 \%(\mathrm{v} / \mathrm{v})$ Penicillin-Streptomycin. All cells were kept at $37^{\circ} \mathrm{C}$ under a humidified atmosphere $\left(5 \% \mathrm{CO}_{2}\right)$.

\section{cAMP assay}

NPR-11 activation was read out in the $G_{i / o}$ pathway by a cAMP reporter gene assay in transiently transfected
HEK293 cells as described previously [23]. Briefly, HEK293 cells were grown to $70 \%$ confluency and transiently co-transfected with the receptor plasmid $(2 \mu \mathrm{g})$ and the reporter gene plasmid pGL4.29 [luc2P/ CRE/Hygro] (Promega; $2 \mu \mathrm{g}$ ) with MetafectenePro (Biontex). Cells were then re-seeded into 384-well plates. On the next day, the medium was removed, and the cells were stimulated with peptide solution $(20 \mu \mathrm{l})$ containing $5 \mu \mathrm{M}$ forskolin (stimulating intracellular cAMP levels) in DMEM and incubated for $4 \mathrm{~h}$. Luciferase substrate OneGlo in lysis buffer (Promega) was added and incubated for $5 \mathrm{~min}$. Luminescence was measured in a microplate reader (Tecan Spark). Data analysis was performed with GraphPad Prism version 5.03 (GraphPad Software) and is presented as $\mathrm{x}$-fold of forskolin.

$\mathrm{G}_{\mathrm{s}}$-coupling of LAT-1, quantified by detection of intracellular cAMP accumulation, was measured using an AlphaScreen cAMP detection kit (PerkinElmer, USA). Briefly, COS-7 cells (15,000 cells/ well) were transfected in 96-well plates with either $200 \mathrm{ng}$ of LAT-1-encoding plasmid or empty vector using Lipofectamine2000 (ThermoFisher Scientific). $48 \mathrm{~h}$ post transfection, the cells were stimulated with $100 \mu \mathrm{M}$ peptide solution in HBSS containing $1 \mathrm{mM}$ 3-isobutyl-1-methylxanthine (IBMX) and 1\% DMSO and control buffer without peptide for $30 \mathrm{~min}$ at $37^{\circ} \mathrm{C}$. Subsequently, the medium was displaced with lysis buffer (5 mM HEPES, 0.3\% Tween20, 0.1\% BSA, 1 mM IBMX, pH 7.6) and plates were frozen at $-80^{\circ} \mathrm{C}$ until further use. The following steps were conducted as stated in the manufactures' protocol of the AlphaScreen cAMP detection kit (PerkinElmer, USA) and an EnVision plate reader (PerkinElmer, USA) was used to detect the fluorescence. The data were analyzed with GraphPad Prism version 6 (GraphPad Software) are presented in $\mathrm{x}$-fold over the corresponding empty vector control.

\section{Fluorescence microscopy and image processing}

To determine the distribution of TAM-labeled peptides in worms in vivo, confocal fluorescence microscopy was performed. Wild-type worms were anesthetized with 30 $\mathrm{mM} \mathrm{NaN}_{3}$ and either intact or scratched incubated with $5 \mu \mathrm{M}$ TAM-FLP-34-1/ TAM-pLAT-1 and their corresponding scrambled versions in $\mathrm{H}_{2} \mathrm{O}+0.5 \%$ BSA for 10 min. After having been washed once in $\mathrm{H}_{2} \mathrm{O}+0.5 \%$ BSA, worms were mounted on a microscopy slide containing a $2 \%$ agar pad and a drop of $\mathrm{H}_{2} \mathrm{O}+0.5 \%$ BSA. Images were recorded as stacks with spatial spacing of $2 \mu \mathrm{m}$. Fluorescence was tracked with a Leica DMi 8 microscope (model TL LED, 20x/ 0.75 immersions oil objective) and a DPSS 61 Laser (excitation $=561 \mathrm{~nm}$, emission $=566-700 \mathrm{~nm})$ at room temperature. Images were recorded with a Leica DFC9000 GTC camera and corresponding software (Leica Application Suite X). 
Contrast, brightness and stack overlay were processed using Fiji [69].

Distribution of the CAAX::mNG fusion protein was determined in intact nematodes expressing CAAX::mNG with an argon laser on $488 \mathrm{~nm}$ excitation and 493-550 $\mathrm{nm}$ emission with the same technique as described above. The same settings were used to image Nluc:: NPR-11::GFP and Nluc::LAT-1::GFP.

Localization of NPR-11::eCFP and CAAX::mNG before and after TAM-FLP-34-1 stimulation was determined in HEK293 cells. The cells were grown on 8-well $\mu$-slides (Ibiditreat) to a confluency of $70-80 \%$ and transfected with $1 \mu \mathrm{g}$ vector DNA (4:1 npr11::eCFP over CAAX:: mNG) using Lipofectamine2000 (ThermoFisher Scientific) following the manufacturer's protocol. On the next day, medium was changed to OptiMEM (Invitrogen Life Technologies) for imaging.

Potential co-localization with recycling endosomes was assessed from co-expression of rab11-eCFP (kind gift from R. Schülein, Leibniz-Institute of Molecular Pharmacology, Berlin, Germany), by transfecting plasmids encoding NPR-11::eYFP and rab11::eCFP in a 9:1 ratio (total $1 \mu \mathrm{g}$ vector DNA) using Lipofectamine2000.

Potential co-localization with lysosomes was investigated in cells expressing only NPR-11:eYFP $(1 \mu \mathrm{g}$ vector DNA transfected with Lipofectamine2000 as described above), and lysosomes were stained for 30 min with Lysotracker blue, (Invitrogen) before peptide stimulation.

Cells were examined before, $30 \mathrm{~min}$ and $60 \mathrm{~min}$ after peptide stimulation (100 nM TAM-FLP-34-1 in OptiMEM), as well as $30 \mathrm{~min}$ and $60 \mathrm{~min}$ after agonist washout $(3 \times 5$ times with warm OptiMEM). Images were acquired at $37^{\circ} \mathrm{C}$ using an Axiovert Observer $\mathrm{Z1}$ microscope (with Apotome, Plan-Apochromat 63x/1.40 Oil DIC objective, filter 47 (436(20)/480(40) for eCFP with acquisition time $1000 \mathrm{~ms}$; filter $46(500(20) / 535(30))$ for eYFP and $\mathrm{mNG}$ with acquisition time $2000 \mathrm{~ms}$; and filter 31 (565(30)/620(60) for TAM with acquisition time $400 \mathrm{~ms}$; Carl Zeiss). Acquisition time was identical in all experiments and all pictures were processed in the same way.

Processed images were stacked in ImageJ [70] and analyzed as follows: Membrane fluorescence in Fig. 5A was measured from 5 cross-sections per cell, expressing both NPR-11::eCFP and CAAX::mNG, using the plugin "Stack $\rightarrow$ measure Stack", which basically reslices the stack and outputs the maximum fluorescence in each channel. Quantification represents the mean of the maximum membrane fluorescence from three independent experiments with each $N \geq 10$ cells, and five cross sections per cell. Linescans in Fig. 6 were generated from a selected line in the image stack using "Stack $\rightarrow$ Reslice" and the fluorescence intensity was then normalized for each channel.

\section{Abbreviations}

BiFC: Bimolecular fluorescence complementation; BRET: Bioluminescence resonance energy transfer; C. elegans: Caenorhabditis elegans; DAP: 2,3diaminoproprionic acid; EC $_{50}$ : Half-maximal efficiency; eCFP: Enhanced cyan fluorescent protein; FLP: FMRF-like peptides; FRET: Fluorescence resonance energy transfer; GPCR: G protein-coupled receptor; kanR: Kanamycin resistance; $K_{d}$ : Dissociation constant; $K_{i}$ : Inhibitory constant; LAT-1: Latrophilinlike 1; mNG: mNeonGreen; Nanoluc: Nanoluciferase; NPR-11: Neuropeptide receptor 11; NPY: Neuropeptide Y; Rab11: -Ras-related protein 11; rpl28p: Ribosomal promotor 28; scr: Scrambled; TAM: 5(6)-

carboxytetramethylrhodamine

\section{Supplementary Information}

The online version contains supplementary material available at https://doi. org/10.1186/s12860-022-00405-w.

\section{Additional file 1. Supplementary material.}

\section{Acknowledgements}

The authors are grateful to Annette G. Beck-Sickinger for long-standing support and thank Paul Hoppenz for assistance with synthesis of LAT-1 peptides and Ralf Schülein (Leibniz-Institute of Molecular Pharmacology, Berlin, Germany) for providing the human ras-related in brain (rab)11a-enhanced cyan fluorescent protein (eCFP) plasmid.

\section{Authors' contributions}

VEG, AK and SP conceived and designed the study. VEG, MMG and AK conducted the experiments. TS, MMG, VEG, AK and SP analyzed and discussed the data. VEG and SP wrote the manuscript with contributions of all co-authors. All authors read and agreed to the final version of the manuscript.

\section{Funding}

This study was funded by the Free State of Saxony, Ministry for Higher Education, Research and the Arts (SMWK, grant 100316655) and by the Deutsche Forschungsgemeinschaft (DFG, German Research Foundation) through CRC 1423, project number 421152132, subprojects B03, C04, and Z03, as well as FOR 2149, project number 265992651, project P02. The funding bodies had no role in the study design, collection and interpretation of the data. Open Access funding enabled and organized by Projekt DEAL.

\section{Availability of data and materials}

All data generated or analyzed during this study are included in this published article and its supplementary information files.

\section{Declarations}

Ethics approval and consent to participate Not applicable.

\section{Consent for publication}

Not applicable.

\section{Competing interests}

The authors declare that they have no competing interests.

\section{Author details}

${ }^{1}$ Rudolf Schönheimer Institute of Biochemistry, Medical Faculty, Leipzig University, 04103 Leipzig, Germany. ${ }^{2}$ Institute of Cell Biology, Department of Biology, Heinrich Heine University Düsseldorf, 40225 Düsseldorf, Germany. ${ }^{3}$ Institute of Biochemistry, Faculty of Life Sciences, Leipzig University, 04103 Leipzig, Germany.

Received: 23 August 2021 Accepted: 11 January 2022

Published online: 31 January 2022

\section{References}

1. Robers MB, Dart ML, Woodroofe CC, Zimprich CA, Kirkland TA, Machleidt T, et al. Target engagement and drug residence time can be observed in 
living cells with BRET. Nat Commun. 2015;6(1):10091. https://doi.org/10.103 8/ncomms10091.

2. Stoddart LA, Johnstone EKM, Wheal AJ, Goulding J, Robers MB, Machleidt T, et al. Application of BRET to monitor ligand binding to GPCRs. Nat Methods. 2015;12(7):661-3. https://doi.org/10.1038/nmeth.3398.

3. Pfleger KDG, Eidne KA. Illuminating insights into protein-protein interactions using bioluminescence resonance energy transfer (BRET). Nat Methods. 2006;3(3):165-74. https://doi.org/10.1038/nmeth841.

4. Weihs F, Wang J, Pfleger KDG, Dacres $\mathrm{H}$. Experimental determination of the bioluminescence resonance energy transfer (BRET) Forster distances of NanoBRET and red-shifted BRET pairs. Anal Chim Acta X. 2020;6:100059. https://doi.org/10.1016/j.acax.2020.100059.

5. Hall MP, Unch J, Binkowski BF, Valley MP, Butler BL, Wood MG, et al. Engineered luciferase reporter from a deep sea shrimp utilizing a novel imidazopyrazinone substrate. ACS Chem Biol. 2012;7(11):1848-57. https:// doi.org/10.1021/cb3002478.

6. Machleidt T, Woodroofe CC, Schwinn MK, Méndez J, Robers MB, Zimmerman K, et al. NanoBRET--A novel BRET platform for the analysis of protein-protein interactions. ACS Chem Biol. 2015;10(8):1797-804. https:// doi.org/10.1021/acschembio.5b00143.

7. Lan T-H, Liu Q, Li C, Wu G, Lambert NA. Sensitive and high resolution localization and tracking of membrane proteins in live cells with BRET. Traffic (Copenhagen, Denmark). 2012;13(11):1450-6.

8. Namkung Y, Le Gouill C, Lukashova V, Kobayashi H, Hogue M, Khoury E, et al. Monitoring $\mathrm{G}$ protein-coupled receptor and $\beta$-arrestin trafficking in live cells using enhanced bystander BRET. Nat Commun. 2016;7(1):12178. https://doi.org/10.1038/ncomms12178.

9. Eyre NS, Aloia AL, Joyce MA, Chulanetra M, Tyrrell DL, Beard MR. Sensitive luminescent reporter viruses reveal appreciable release of hepatitis $C$ virus NS5A protein into the extracellular environment. Virology. 2017;507:20-31. https://doi.org/10.1016/j.virol.2017.04.003.

10. Angers S, Salahpour A, Joly E, Hilairet S, Chelsky D, Dennis M, et al. Detection of beta 2-adrenergic receptor dimerization in living cells using bioluminescence resonance energy transfer (BRET). Proc Natl Acad Sci U S A. 2000;97(7):3684-9. https://doi.org/10.1073/pnas.97.7.3684.

11. Yan Y, Xu TH, Harikumar KG, Miller LJ, Melcher K, Xu HE. Dimerization of the transmembrane domain of amyloid precursor protein is determined by residues around the gamma-secretase cleavage sites. J Biol Chem. 2017; 292(38):15826-37. https://doi.org/10.1074/jbc.M117.789669.

12. Stoddart LA, Kilpatrick LE, Hill SJ. NanoBRET approaches to study ligand binding to GPCRs and RTKs. Trends Pharmacol Sci. 2018;39(2):136-47. https://doi.org/10.1016/j.tips.2017.10.006.

13. Dale NC, Johnstone EKM, White CW, Pfleger KDG. NanoBRET: the bright future of proximity-based assays. Front Bioeng Biotechnol. 2019;7:56. https:// doi.org/10.3389/fbioe.2019.00056.

14. Hikita T, Miyata M, Watanabe R, Oneyama C. In vivo imaging of long-term accumulation of cancer-derived exosomes using a BRET-based reporter. Sci Rep. 2020;10(1):16616. https://doi.org/10.1038/s41598-020-73580-5.

15. Schaub FX, Reza MS, Flaveny CA, Li W, Musicant AM, Hoxha S, et al. Fluorophore-NanoLuc BRET reporters enable sensitive in vivo optical imaging and flow cytometry for monitoring tumorigenesis. Cancer Res. 2015;75(23):5023-33. https://doi.org/10.1158/0008-5472.CAN-14-3538.

16. Kuchimaru T, Suka T, Hirota K, Kadonosono T, Kizaka-Kondoh S. A novel injectable BRET-based in vivo imaging probe for detecting the activity of hypoxia-inducible factor regulated by the ubiquitin-proteasome system. Sci Rep. 2016;6(1):34311. https://doi.org/10.1038/srep34311.

17. Tang Y, Parag-Sharma K, Amelio AL, Cao Y. A Bioluminescence Resonance Energy Transfer-Based Approach for Determining Antibody-Receptor Occupancy In Vivo. iScience. 2019;15:439-51. https://doi.org/10.1016/j.isci.2 019.05.003.

18. Alcobia DC, Ziegler Al, Kondrashov A, Comeo E, Mistry S, Kellam B, et al. Visualizing Ligand Binding to a GPCR In Vivo Using NanoBRET. iScience. 2018;6:280-8. https://doi.org/10.1016/j.isci.2018.08.006.

19. Dragulescu-Andrasi A, Chan CT, De A, Massoud TF, Gambhir SS Bioluminescence resonance energy transfer (BRET) imaging of proteinprotein interactions within deep tissues of living subjects. Proc Natl Acad Sci U S A. 2011;108(29):12060-5. https://doi.org/10.1073/pnas.1100923108.

20. Lagido C, Pettitt J, Flett A, Glover LA. Bridging the phenotypic gap: real-time assessment of mitochondrial function and metabolism of the nematode Caenorhabditis elegans. BMC Physiol. 2008;8(1):7. https://doi.org/10.1186/14 72-6793-8-7.
21. Sfarcic I, Bui T, Daniels EC, Troemel ER. Nanoluciferase-based method for detecting gene expression in Caenorhabditis elegans. Genetics. 2019;213(4): 1197-207. https://doi.org/10.1534/genetics.119.302655.

22. Heppert JK, Dickinson DJ, Pani AM, Higgins CD, Steward A, Ahringer J, et al. Comparative assessment of fluorescent proteins for in vivo imaging in an animal model system. Mol Biol Cell. 2016;27(22):3385-94. https://doi.org/10.1 091/mbc.e16-01-0063.

23. Gershkovich MM, Groß VE, Kaiser A, Prömel S. Pharmacological and functional similarities of the human neuropeptide $Y$ system in $C$. elegans challenges phylogenetic views on the FLP/NPR system. Cell Commun Signal CCS. 2019;17(1):123.

24. Gøtzsche CR, Woldbye DPD. The role of NPY in learning and memory. Neuropeptides. 2016;55:79-89. https://doi.org/10.1016/j.npep.2015.09.010.

25. Yulyaningsih E, Zhang L, Herzog H, Sainsbury A. NPY receptors as potential targets for anti-obesity drug development. Br J Pharmacol. 2011;163(6): 1170-202. https://doi.org/10.1111/j.1476-5381.2011.01363.x.

26. Elphick MR, Mirabeau O, Larhammar D. Evolution of neuropeptide signalling systems. J Exp Biol. 2018;221(Pt 3):jeb151092.

27. Fadda M, Hasakiogullari I, Temmerman L, Beets I, Zels S, Schoofs L. Regulation of feeding and metabolism by neuropeptide $F$ and short neuropeptide F in invertebrates. Front Endocrinol. 2019;10:64. https://doi. org/10.3389/fendo.2019.00064.

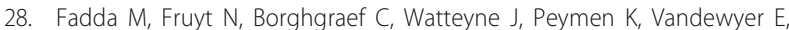
et al. NPY/NPF-related neuropeptide FLP-34 signals from serotonergic neurons to modulate aversive olfactory learning in Caenorhabditis elegans. J Neurosci. 2020;40(31):6018-34. https://doi.org/10.1523/ JNEUROSCI.2674-19.2020.

29. Moreno-Salinas AL, Avila-Zozaya M, Ugalde-Silva P, Hernandez-Guzman DA, Missirlis F, Boucard AA. Latrophilins: a neuro-centric view of an evolutionary conserved adhesion G protein-coupled receptor subfamily. Front Neurosci. 2019;13:700. https://doi.org/10.3389/fnins.2019.00700.

30. Langenhan T, Prömel S, Mestek L, Esmaeili B, Waller-Evans H, Hennig C, et al. Latrophilin signaling links anterior-posterior tissue polarity and oriented cell divisions in the C. elegans embryo. Dev Cell. 2009;17(4):494504. https://doi.org/10.1016/j.devcel.2009.08.008.

31. Müller A, Winkler J, Fiedler F, Sastradihardja T, Binder C, Schnabel R, et al. Oriented Cell Division in the C. elegans Embryo Is Coordinated by G-Protein Signaling Dependent on the Adhesion GPCR LAT-1. PLoS Genet. 2015: 11(10):e1005624.

32. Liebscher I, Schön J, Petersen SC, Fischer L, Auerbach N, Demberg LM, et al. A tethered agonist within the ectodomain activates the adhesion $\mathrm{G}$ protein-coupled receptors GPR126 and GPR133. Cell Rep. 2014;9(6):2018-26. https://doi.org/10.1016/j.celrep.2014.11.036.

33. Stacer AC, Nyati S, Moudgil P, lyengar R, Luker KE, Rehemtulla A, et al. NanoLuc reporter for dual luciferase imaging in living animals. Mol Imaging. 2013;12(7):1-13. https://doi.org/10.2310/7290.2013.00062.

34. Peymen K, Watteyne J, Frooninckx L, Schoofs L, Beets I. The FMRFamide-like peptide family in nematodes. Front Endocrinol (Lausanne). 2014;5:90. https://doi.org/10.3389/fendo.2014.00090.

35. Gershkovich MM, Gross VE, Vu O, Schoeder CT, Meiler J, Promel S, et al. Structural perspective on ancient neuropeptide Y-like system reveals Hallmark features for peptide recognition and receptor activation. J Mol Biol. 2021;433(13):166992. https://doi.org/10.1016/j.jmb.2021.166992.

36. Demberg LM, Winkler J, Wilde C, Simon KU, Schon J, Rothemund S, et al. Activation of adhesion $\mathrm{G}$ protein-coupled receptors: AGONIST SPECIFICITY OF STACHEL SEQUENCE-DERIVED PEPTIDES. J Biol Chem. 2017;292(11):438394. https://doi.org/10.1074/jbc.M116.763656.

37. Clarke S. Protein isoprenylation and methylation at carboxyl-terminal cysteine residues. Annu Rev Biochem. 1992;61 (1):355-86. https://doi.org/1 0.1146/annurev.bi.61.070192.002035.

38. Ullrich $\mathrm{O}$, Reinsch $\mathrm{S}$, Urbe $\mathrm{S}$, Zerial M, Parton $\mathrm{RG}$. Rab11 regulates recycling through the pericentriolar recycling endosome. J Cell Biol. 1996;135(4):91324. https://doi.org/10.1083/jcb.135.4.913

39. Taylor A, Sharkey J, Plagge A, Wilm B, Murray P. Multicolour in vivo bioluminescence imaging using a NanoLuc-based BRET reporter in combination with firefly luciferase. Contrast Media Mol Imaging. 2018;2018: 2514796-10. https://doi.org/10.1155/2018/2514796.

40. Rodríquez-Palero MJ, López-Díaz A, Marsac R, Gomes J-E, Olmedo M, ArtalSanz M. An automated method for the analysis of food intake behaviour in Caenorhabditis elegans. Sci Rep. 2018;8(1):3633. https://doi.org/10.1038/s41 598-018-21964-z. 
41. Lagido C, Pettitt J, Porter AJ, Paton GI, Glover LA. Development and application of bioluminescent Caenorhabditis elegans as multicellular eukaryotic biosensors. FEBS Lett. 2001;493(1):36-9. https://doi.org/10.1016/ S0014-5793(01)02271-2.

42. Goya ME, Romanowski A, Caldart CS, Bénard CY, Golombek DA. Circadian rhythms identified in Caenorhabditis elegans by in vivo long-term monitoring of a bioluminescent reporter. Proc Natl Acad Sci U S A. 2016; 113(48):E7837-45. https://doi.org/10.1073/pnas.1605769113.

43. Hunt-Newbury R, Viveiros R, Johnsen R, Mah A, Anastas D, Fang L, et al. High-throughput in vivo analysis of gene expression in Caenorhabditis elegans. PLoS Biol. 2007;5(9):e237. https://doi.org/10.1371/journal.pbio. 0050237.

44. McKay SJ, Johnsen R, Khattra J, Asano J, Baillie DL, Chan S, et al. Gene expression profiling of cells, tissues, and developmental stages of the nematode C. elegans. Cold Spring Harb Symp Quant Biol. 2003;68(0):159-69. https://doi.org/10.1101/sqb.2003.68.159.

45. Willson J, Amliwala K, Davis A, Cook A, Cuttle MF, Kriek N, et al. Latrotoxin receptor signaling engages the UNC-13-dependent vesicle-priming pathway in C. elegans. Curr Biol CB. 2004;14(15):1374-9. https://doi.org/10.1016/j. cub.2004.07.056

46. Schuck P. Analytical ultracentrifugation as a tool for studying protein interactions. Biophys Rev. 2013;5(2):159-71. https://doi.org/10.1007/s12551013-0106-2.

47. Some D, Razinkov V. High-throughput analytical light scattering for protein quality control and characterization. Methods Mol Biol. 2019;2025:335-59. https://doi.org/10.1007/978-1-4939-9624-7_16.

48. Soave M, Stoddart LA, White CW, Kilpatrick LE, Goulding J, Briddon SJ, et al. Detection of genome-edited and endogenously expressed $\mathrm{G}$ proteincoupled receptors. FEBS J. 2021;288(8):2585-601.

49. Banerjee S, Versaw WK, Garcia LR. Imaging cellular inorganic phosphate in Caenorhabditis elegans using a genetically encoded FRET-based biosensor. PLoS One. 2015;10(10):e0141128. https://doi.org/10.1371/journal.pone. 0141128.

50. Nagarajan A, Bodhicharla R, Winter J, Anbalagan C, Morgan K, Searle M, et al. A fluorescence resonance energy transfer assay for monitoring aSynclein aggregation in a Caenorhabditis Elegans model for Parkinson's disease. CNS Neurol Disord Drug Targets. 2015;14(8):1054-68. https://doi. org/10.2174/1871527314666150821110538.

51. Shyu YJ, Hiatt SM, Duren HM, Ellis RE, Kerppola TK, Hu C-D. Visualization of protein interactions in living Caenorhabditis elegans using bimolecular fluorescence complementation analysis. Nat Protoc. 2008;3(4):588-96. https://doi.org/10.1038/nprot.2008.16.

52. Hiatt SM, Shyu YJ, Duren HM, Hu C-D. Bimolecular fluorescence complementation (BiFC) analysis of protein interactions in Caenorhabditis elegans. Methods (San Diego, Calif). 2008;45(3):185-91.

53. Calebiro D, Godbole A. Internalization of G-protein-coupled receptors: implication in receptor function, physiology and diseases. Best Pract Res Clin Endocrinol Metab. 2018;32(2):83-91. https://doi.org/10.1016/j.beem.201 8.01.004.

54. Ziffert I, Kaiser A, Hoppenz P, Morl K, Beck-Sickinger AG. Shuttling of peptide-drug conjugates by $\mathrm{G}$ protein-coupled receptors is significantly improved by pulsed application. ChemMedChem. 2021;16(1):164-78. https://doi.org/10.1002/cmdc.202000490.

55. Babilon S, Morl K, Beck-Sickinger AG. Towards improved receptor targeting: anterograde transport, internalization and postendocytic trafficking of neuropeptide Y receptors. Biol Chem. 2013;394(8):921-36. https://doi.org/1 0.1515/hsz-2013-0123.

56. Bacaj T, Shaham S. Temporal control of cell-specific transgene expression in Caenorhabditis elegans. Genetics. 2007;176(4):2651-5. https://doi.org/10.1 534/genetics.107.074369.

57. Wei X, Potter CJ, Luo L, Shen K. Controlling gene expression with the Q repressible binary expression system in Caenorhabditis elegans. Nat Methods. 2012;9(4):391-5. https://doi.org/10.1038/nmeth.1929.

58. Zhang L, Ward JD, Cheng Z, Dernburg AF. The auxin-inducible degradation (AID) system enables versatile conditional protein depletion in C. elegans. Development (Cambridge, England). 2015;142(24):4374-84.

59. Mäde V, Els-Heindl S, Beck-Sickinger AG. Automated solid-phase peptide synthesis to obtain therapeutic peptides. Beilstein J Org Chem. 2014;10: 1197-212. https://doi.org/10.3762/bjoc.10.118.

60. Dinger MC, Bader JE, Kobor AD, Kretzschmar AK, Beck-Sickinger AG. Homodimerization of neuropeptide y receptors investigated by fluorescence resonance energy transfer in living cells. J Biol Chem. 2003; 278(12):10562-71. https://doi.org/10.1074/jbc.M205747200.

61. Voutev R, Hubbard EJA. A "FLP-out" system for controlled gene expression in Caenorhabditis elegans. Genetics. 2008;180(1):103-19. https://doi.org/10.1 534/genetics. 108.090274.

62. Warming S, Costantino N, Court DL, Jenkins NA, Copeland NG. Simple and highly efficient BAC recombineering using galK selection. Nucleic Acids Res. 2005;33(4):e36. https://doi.org/10.1093/nar/gni035.

63. Brenner S. The genetics of Caenorhabditis elegans. Genetics. 1974;77(1):7194. https://doi.org/10.1093/genetics/77.1.71.

64. Mello C, Fire A. DNA transformation. Methods Cell Biol. 1995;48:451-82. https://doi.org/10.1016/S0091-679X(08)61399-0.

65. Mello CC, Kramer JM, Stinchcomb D, Ambros V. Efficient gene transfer in C. elegans: extrachromosomal maintenance and integration of transforming sequences. EMBO J. 1991;10(12):3959-70. https://doi.org/10.1002/j.1460-2 075.1991.tb04966.x.

66. Radman I, Greiss S, Chin JW. Efficient and rapid C. elegans transgenesis by bombardment and hygromycin B selection. PLoS One. 2013;8(10):e76019.

67. Kaiser A, Hempel C, Wanka L, Schubert M, Hamm HE, Beck-Sickinger AG. G protein preassembly rescues efficacy of W6.48 toggle mutations in neuropeptide Y2 receptor. Mol Pharmacol. 2018;93(4):387-401. https://doi. org/10.1124/mol.117.110544.

68. Tang T, Hartig C, Chen Q, Zhao W, Kaiser A, Zhang X, et al. Structural basis for ligand recognition of the neuropeptide $Y$ Y 2 receptor. Nat Commun. 2021;12(1):737. https://doi.org/10.1038/s41467-021-21030-9.

69. Schindelin J, Arganda-Carreras I, Frise E, Kaynig V, Longair M, Pietzsch T, et al. Fiji: an open-source platform for biological-image analysis. Nat Methods. 2012;9(7):676-82. https://doi.org/10.1038/nmeth.2019.

70. Schneider CA, Rasband WS, Eliceiri KW. NIH image to ImageJ: 25 years of image analysis. Nat Methods. 2012;9(7):671-5. https://doi.org/10.1038/ nmeth.2089.

\section{Publisher's Note}

Springer Nature remains neutral with regard to jurisdictional claims in published maps and institutional affiliations.

Ready to submit your research? Choose BMC and benefit from:

- fast, convenient online submission

- thorough peer review by experienced researchers in your field

- rapid publication on acceptance

- support for research data, including large and complex data types

- gold Open Access which fosters wider collaboration and increased citations

- maximum visibility for your research: over $100 \mathrm{M}$ website views per year

At BMC, research is always in progress.

Learn more biomedcentral.com/submissions 